Summer 2018

\title{
The Role of Ecological Interactions in Saltmarsh Geomorphic Processes
}

Bethany Lynn Williams

William \& Mary - Virginia Institute of Marine Science, bwilliams@vims.edu

Follow this and additional works at: https://scholarworks.wm.edu/etd

Part of the Ecology and Evolutionary Biology Commons

\section{Recommended Citation}

Williams, Bethany Lynn, "The Role of Ecological Interactions in Saltmarsh Geomorphic Processes" (2018). Dissertations, Theses, and Masters Projects. William \& Mary. Paper 1530192504.

http://dx.doi.org/10.25773/v5-7mch-yc93

This Thesis is brought to you for free and open access by the Theses, Dissertations, \& Master Projects at W\&M ScholarWorks. It has been accepted for inclusion in Dissertations, Theses, and Masters Projects by an authorized administrator of W\&M ScholarWorks. For more information, please contact scholarworks@wm.edu. 
The role of ecological interactions in saltmarsh geomorphic processes

$\overline{ }$

A Thesis

Presented to

The Faculty of the School of Marine Science

The College of William and Mary in Virginia

\author{
In Partial Fulfillment \\ of the Requirements for the Degree of \\ Master of Science
}

by

Bethany L. Williams

May 2018 


\section{APPROVAL PAGE}

This thesis is submitted in partial fulfillment of

the requirements for the degree of

Master of Science

Bethany L. Williams

Approved by the Committee, January 2017

\begin{tabular}{c}
\hline $\begin{array}{c}\text { David S. Johnson, Ph.D } \\
\text { Committee Chair / Advisor }\end{array}$ \\
\hline Mark J. Brush, Ph.D \\
\hline Rochelle D. Seitz, Ph.D \\
\hline
\end{tabular}

Matthew L. Kirwan, Ph.D 


\section{Table of Contents}

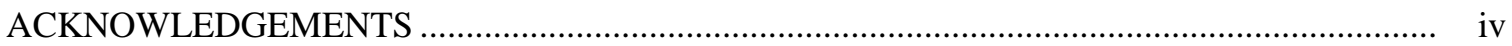

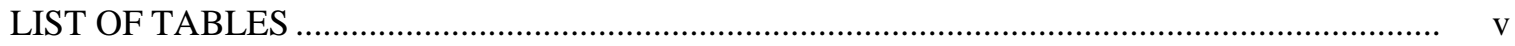

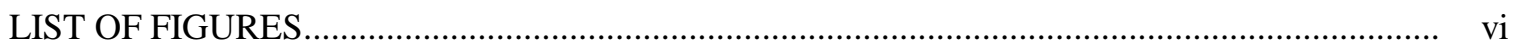

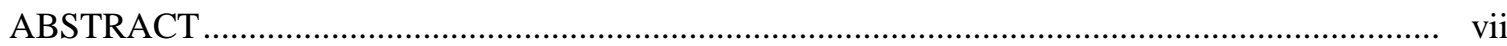

INTRODUCTION

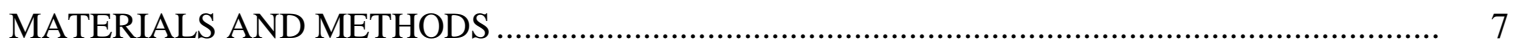

Effect of Uca on Spartina alterniflora production and sediment deposition ............................ 7

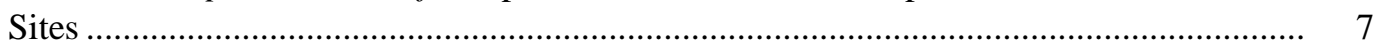

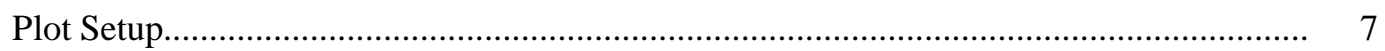

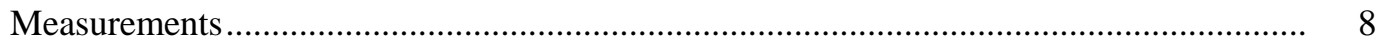

Statistical Analyses............................................................................................. 9

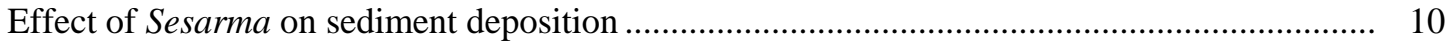

Plot Setup

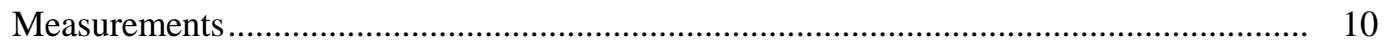

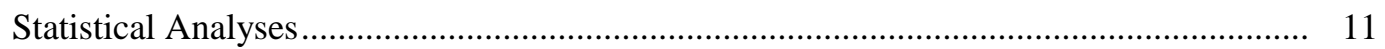

Effect of Uca and Sesarma on above- and belowground components of vertical accretion ....... 11

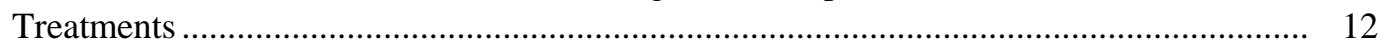

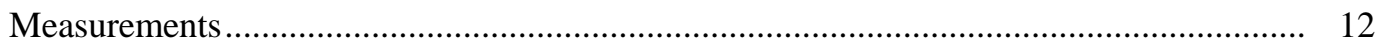

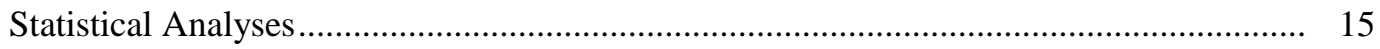

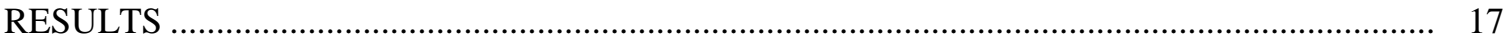

Effect of Uca on Spartina alternifora production and sedimentation ..................................... 17

Effect of Sesarma on sedimentation.............................................................................. 17

Effects of Uca and Sesarma on above and belowground components of vertical accretion ....... 18

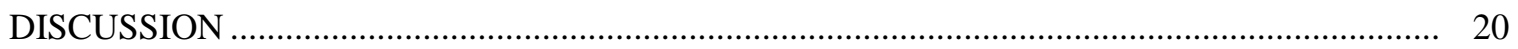

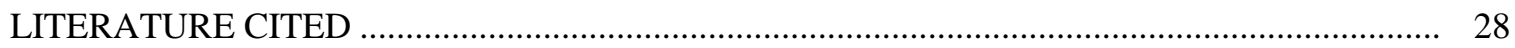




\section{ACKNOWLEDGEMENTS}

I would like to thank my advisor Dr. David Johnson for meaningful mentorship throughout the entirety of my thesis project. Dr. Johnson has dedicated significant time to developing me as a scientist and a person, while supporting my career goals and professional development. I am forever thankful for his mentorship and support. I also thank my thesis committee for their helpful insight and contribution to the design and execution of this project.

I would also like to thank my funding sources: Virginia Sea Grant, VIMS Office of Academic Studies, and the Garden Club of America for their fiscal support throughout the duration of my thesis project. I thank Virginia Sea Grant for providing me with a host of skills and professional development opportunities that I will take with me beyond my time at VIMS. Additionally, I thank all the sites that allowed me to tromp around their marshes chasing fiddler crabs and plants: Chesapeake Bay National Estuarine Research Reserve, Virginia Coast Reserve Long-Term Ecological Research Site, Narragansett Bay National Estuarine Research Reserve, and Cape Cod National Seashore.

In addition, I would like to thank the many members of the Global Change Ecology Lab (JLab) who assisted me in the field, lab, and everywhere in between: Cynthia Crowley, Danielle Doucette, Caroline Failon, Katherine Longmire, Manisha Pant, William Schuebert, Serina Sebilian, and Viola Yu. I would also like to thank honorary members of the lab for their assistance statistically, artistically, and in the field: Daniel Coleman, Daniel Crear, Lauren Huey, Henry Lane, and my dog Murphy. All provided me with significant support, both academically and emotionally, throughout the course of my thesis.

Finally, I would like to thank the VIMS graduate student community for their support and comradery throughout my time here. 


\section{LIST OF TABLES}

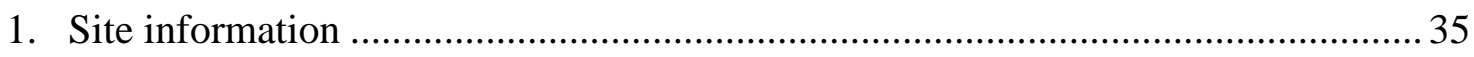

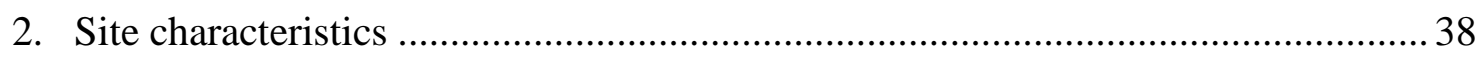

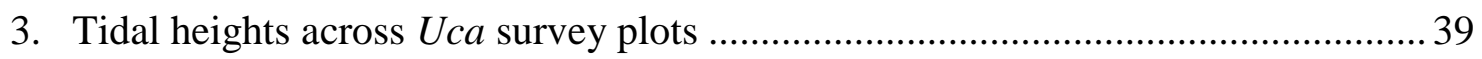

4. Spartina biomass and Uca density across Sesarma grazing intensity ................... 43

5. Tidal heights across Sesarma grazing intensity ............................................... 44

6. Sesarma burrow densities across grazing intensity and sites............................. 47 


\section{LIST OF FIGURES}

1. Conceptual diagram for the interaction between ecology and

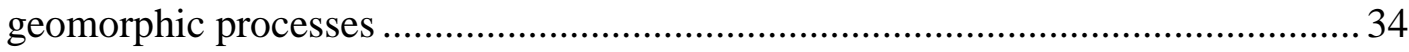

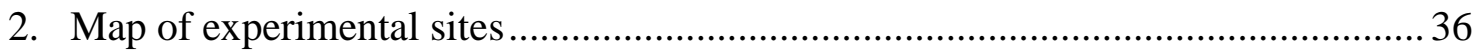

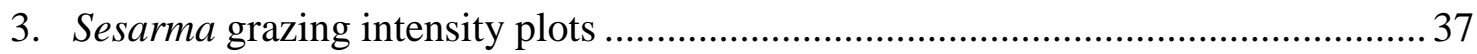

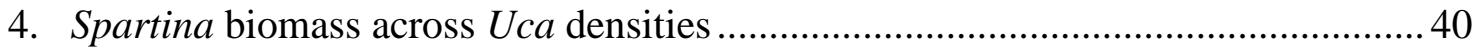

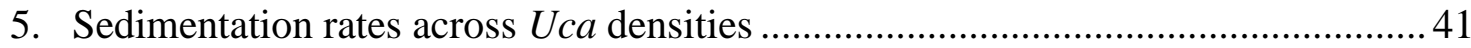

6. Soil strength across $U c a$ densities........................................................... 42

7. Sedimentation rates and soil strength across Sesarma grazing

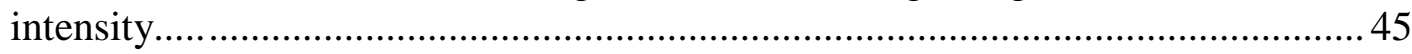

8. Uca burrow density across Sesarma grazing intensity ..................................... 46

9. Cage experiment treatment effect on aboveground Spartina .............................. 48

10. Cage experiment treatment effect on sedimentation rates .................................. 49

11. Cage experiment treatment effect on belowground metrics ................................50

12. Cage experiment treatment effect on root-to-shoot ratio and

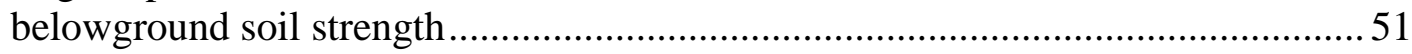

13. Cage experiment treatment effect on belowground processes .............................52

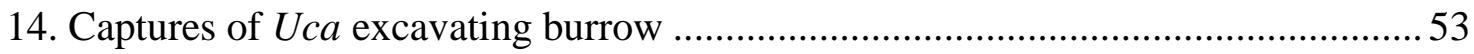




\begin{abstract}
Accelerated sea-level rise poses a significant threat to coastal habitats. Salt marshes are critical coastal ecosystems, providing a host of services such as storm protection, food production, and carbon storage. Persistence of salt marshes in the face of rising sea levels relies, in part, on vertical accretion. Current ecogeomorphic models and empirical studies emphasize the importance of the positive relationship between plant production and vertical accretion via sediment trapping by stems aboveground and belowground organic matter production. Thus, changes in plant production influence salt marsh persistence with sea-level rise. However, studies and models of marsh accretion do not consider the effects of animal-mediated changes in plant production. Here, I tested how two cooccurring marsh crustaceans, Uca pugnax (marsh fiddler crab) and Sesarma reticulatum (purple marsh crab), which have contrasting effects on smooth cordgrass (Spartina alterniflora) production, indirectly influence sediment deposition and belowground organic matter contribution, through observational surveys and field manipulation. $S$. reticulatum feeds directly on $S$. alterniflora, while $U$. pugnax facilitates $S$. alterniflora production through burrowing and biodeposits. I found that $U$. pugnax facilitated $S$. alterniflora biomass in some marshes, but not others. However, this facilitation of $S$. alterniflora biomass did not enhance sediment deposition. U. pugnax had no effect on belowground components of vertical accretion (i.e. root production and decomposition). These results suggest that in isolation, $U$. pugnax has little impact on saltmarsh geomorphic processes. S. reticulatum reduced $S$. alterniflora above- and belowground biomass; however, sediment deposition increased as $S$. alterniflora biomass decreased, contrary to models of ecogeomorphology. This trend was likely due to sediment being resuspended by crab bioturbation, as $U$. pugnax abundances were higher in $S$. reticulatum-grazed areas than in non-grazed areas. When $U$. pugnax occurred in areas of low $S$. reticulatum grazing, $S$. alterniflora biomass and sedimentation was similar to areas with only $U$. pugnax. I suggest that the negative impacts of $S$. reticulatum are exaggerated when intense grazing results in completely unvegetated areas and subsequent increases in $U$. pugnax density, where bioturbation erodes sediments. Thus, while $S$. reticulatum can increase the susceptibility of marsh sediments to physical erosion by removing vegetation, it may also do so by facilitating $U$. pugnax bioturbation. However, when $S$. reticulatum grazing intensity is low, facilitation of $S$. alterniflora growth by $U$. pugnax can mitigate the negative effect of grazing, which suggests that the net effect of these species may depend on their relative abundance. This study demonstrates that ecological interactions, in addition to physical processes, have significant effects on marsh persistence as sea level rises, and merit incorporation into ecogeomorphic models and empirical studies of marsh accretion.
\end{abstract}


The role of ecological interactions in saltmarsh geomorphic processes 


\section{INTRODUCTION}

Salt marshes are among the most productive ecosystems in the world (Mendelssohn and Morris 2002) and provide important ecosystem services such as storm protection, carbon storage, food production, and tourism (Barbier et al. 2011). Habitat loss due to accelerated sea-level rise is a major concern for salt marshes, especially in regions where accelerations of sea-level rise rates are higher than the global average, like Atlantic coast of the United States. Here, the rate sea-level rise is increasing 3-4 times faster than the global average (Sallenger et al. 2012). Salt marsh persistence in the face of sea-level rise relies on landward migration and vertical accretion (Kirwan et al. 2016). Landward migration however, is often inhibited by anthropogenic structures such as roads, sea walls, and houses, causing a coastal squeeze (Pontee 2013). Since $14 \%$ of the United States shoreline has been hardened (Gittman et al. 2015), understanding the factors that influence accretion will be important to predict the vulnerability of salt marshes to accelerated sea-level rise.

For vertical accretion, current ecogeomorphic models, supported by empirical studies, stress the importance of sediment trapping by marsh grass (i.e. smooth cordgrass Spartina alterniflora) and the contribution of organic matter via belowground production (Morris et al. 2002; Fagherazzi et al. 2013a; Morris et al. 2013). Marsh plants are foundation species that slow the flow velocity of water, allowing sediment particles to settle out of the water column onto the marsh surface (Friedrichs and Perry 2001). As marsh grass stem density and biomass increase, sediment deposition is enhanced (Friedrichs and Perry 
2001; Morris et al. 2002; Fagherazzi et al. 2013a). Therefore, changes in primary production can influence accretion rates.

Hydrology, in addition to marsh plants, influences salt marsh vertical accretion. With greater inundation and hydroperiod, the marsh is flooded for a longer period of time, allowing for more sediment deposition to occur, and thus contributing to vertical accretion (Friedrichs and Perry 2001; Fagherazzi et al. 2013a). In addition to sediment delivery, hydrology can control plant production. As flooding increases, Spartina production is stimulated, but in a parabolic pattern, such that when hydroperiods are extremely high, marsh plants drown (Morris et al. 2002; Morris et al. 2013).

Current ecogeomorphic models of marsh accretion focus on physical processes that affect plant production and sediment deposition, but ecological interactions may also be important. Animals can influence saltmarsh plant production (Bertness 1985; Coverdale et al. 2012; Hughes et al. 2014) and thus merit consideration in ecogeomorphic studies of marsh accretion. For instance, facilitation is a positive interaction that occurs when one organism makes the environment more hospitable for another (Stachowicz 2001). Facilitation of aboveground plant biomass could enhance marsh accretion via increased sediment trapping. In contrast to the positive effects of facilitation on plant biomass, herbivory has negative effects on plant production (Silliman and Zieman 2001; Holdredge et al. 2009; Coverdale et al. 2012). Because herbivory can significantly reduce the abundance and biomass of marsh plants, it could potentially inhibit vertical accretion. However, to my knowledge, no tests of how plant-animal interactions affect physical 
processes that influence marsh accretion, such as sediment trapping, have been conducted.

In salt marshes, the marsh fiddler crab, Uca pugnax (hereafter referred to as Uca) and the purple marsh crab, Sesarma reticulatum (hereafter referred to as Sesarma) co-occur in the same tidal zone in salt marshes along the Atlantic coast of the United States (Seiple 1979; Grimes et al. 1989; Johnson 2014). While their direct effects on saltmarsh physical structure have been well studied (e.g., their burrowing activities; Seiple and Salmon 1982; Bertness 1985; McCraith et al. 2003; Hughes et al. 2009; Vu et al. 2017), their indirect effects have received little attention. In terms of aboveground biomass, $U c a$ is a facilitator species that increases the biomass of the cordgrass, Spartina alterniflora (hereafter referred to as Spartina), via nutrient regeneration, biodeposits, and oxygenation of marsh soils (Bertness 1985; Gittman and Keller 2013; Hughes et al. 2014). However, this process is often mediated by soil characteristics (Holdredge et al. 2010; Michaels and Zieman 2013). Generally, by increasing Spartina biomass through burrowing activities, Uca may indirectly facilitate sediment trapping, the aboveground component of marsh accretion. However, burrowing activity by $U c a$ also reduces belowground production and increases decomposition rates (Thomas and Blum 2010; Gittman and Keller 2013). Therefore, they may have contrasting effects on the above- and belowground components of vertical accretion.

In contrast to the facilitative effects of $U c a$ on aboveground biomass of Spartina, Sesarma reduces Spartina biomass through herbivory on both above- and belowground 
plant biomass (Seiple and Salmon 1982; Coverdale et al. 2012). While Sesarma is also a burrowing species, and could facilitate growth similar to Uca through this activity, its grazing offsets any positive effects of burrowing, sometimes resulting in major die-backs of Spartina (Holdredge et al. 2009; Coverdale et al. 2012). Through the negative effect of Sesarma grazing on Spartina biomass, this crab could indirectly decrease sedimentation rates aboveground, in addition to preventing contribution of organic matter belowground, thus indirectly and strongly inhibiting vertical accretion.

The negative effects of Sesarma on plants may be offset by positive effects of other species such as Uca (Gittman and Keller 2013). In New England, Spartina die-offs have occurred where Sesarma is overabundant because of predator release (i.e. a trophic cascade) (Holdredge et al. 2009; Altieri et al 2012). Given the large geographic distribution of Sesarma (Seiple 1979), these die-offs should be widespread in Atlantic salt marshes where removal of predators has increased, but they are not. Facilitation of Spartina by Uca can ameliorate the negative effects of other grazers (Gittman and Keller 2013), and thus may prevent the prevalence of Spartina die-offs via Sesarma herbivory along much of the Atlantic coast.

The overarching goal of this research is to determine how ecological interactions between animals and saltmarsh plants may indirectly influence saltmarsh vertical accretion, using sediment deposition and organic matter contribution as proxies for this process. Specifically, Uca may positively influence vertical accretion by facilitating aboveground Spartina biomass and sedimentation (Figure 1). In contrast, Sesarma may impede vertical 
accretion by grazing above- and belowground biomass of Spartina (Figure 1). However, Uca may ameliorate the negative effects of Sesarma, aboveground, by facilitating Spartina shoot growth. To test these hypotheses, I targeted three specific objectives: 1) Determine how natural variation in Uca density influences Spartina production, and ultimately sediment deposition, 2) determine how natural variations in Sesarma grazing intensity influence sediment deposition, and 3) test the individual and combined effects of Uca and Sesarma on components of vertical accretion via changes in above- and belowground Spartina production, decomposition, and sedimentation, using experimental field manipulations. By incorporating the role of animal-mediated controls on primary production into ecogeomorphic models of marsh accretion, we can more clearly understand the capacity of salt marshes to keep pace, as accelerated sea-level rise threatens these critical coastal ecosystems. 


\section{MATERIALS AND METHODS}

To study the effects of Uca and Sesarma on Spartina production, aboveground sediment deposition, and belowground organic matter contribution, I approached these questions in two ways: 1) field observations and 2) a manipulative experiment. Field observations allowed for measurement of responses across a wide range of marshes, with varying hydroperiods and sediment availabilities, to determine if trends occur across marshes. A manipulative experiment was used to control confounding factors and to measure process rates (e.g., production, decomposition).

\section{Effect of Uca on Spartina alterniflora production and sediment deposition}

Study Sites: I conducted a field survey of five salt marshes (Goodwin Island, Seaford, Virginia; Boxtree Marsh, Machipongo, Virginia; Lower Phillips Creek, Nassawadox, Virginia; Nag Marsh, Prudence Island, Rhode Island; Gut Marsh, Wellfleet, Massachusetts; Figure 2; Table 1) from July-August 2016. These marshes are dominated by Spartina at the low elevations, with a band of S. patens at slightly higher elevations. The Spartina zones are flooded twice daily with the high tides. Sampling at this wide range of sites was done to test the generality of results across marshes with varying hydroperiods and sediment availabilities (Table 2, Table 5).

Plot Setup: Along a 100-m span of each marsh $0.0625 \mathrm{~m}^{2}$ plots were set up in areas with and without $U c a$ burrows ( $\mathrm{n}=8 /$ area type). $U c a$-present plots were interspersed with $U c a$-absent plots. Because sediment concentration decreases with increasing distance 
from the marsh edge (Friedrichs and Perry 2001) each plot, within site, was sampled at similar distances from the marsh edge (Table 2).

Measurements: Sedimentation was measured by deploying two sediment plates in each plot for one week. Sediment plates were constructed by rubber banding a pre-weighed 90 $\mathrm{mm}$ fiberglass filter to a Plexiglas plate, and staking it to the ground so it is flush with the marsh surface (LeMay 2007). Upon collection, fiberglass filters were carefully removed from the sediment plate and dried at $60{ }^{\circ} \mathrm{C}$ to a constant mass, then weighed. To examine only inorganic deposition, filters were combusted at $550{ }^{\circ} \mathrm{C}$ for two hours and weighed. Because the sedimentation plates experienced high levels of fiddler crab biodeposition (fecal pellets), a site-specific correction factor was used to adjust the masses of the filters after deployment. This correction factor was calculated by weighing individual fecal pellets from each site ( $\mathrm{n}=50 /$ site) to determine an average fecal pellet weight for each site. Then, fecal pellets on filters were enumerated and multiplied by the average pellet weight for that site. This value was then subtracted from the total mass of the filter and sediment, to provide a more accurate value of sedimentation. Inorganic deposition rate was calculated using the following equation:

Sedimentation Rate $(\mathrm{mg} /$ day $)=\frac{(\text { Corrected total ash mass }(\mathrm{mg}) \text {-Filter mass }(\mathrm{mg}))}{\# \text { days deployed }} \quad$ Equation 1 Spartina production was measured using standing stock biomass as a proxy. After sedimentation plates were collected, all plants within the $0.0625 \mathrm{~m}^{2}$ plot were collected by clipping the plants at the marsh surface. Live and dead stems were washed, separated, enumerated, then dried at $60{ }^{\circ} \mathrm{C}$ to a constant mass and weighed. Uca burrow densities were measured by enumerating the number of burrows $(>1 \mathrm{~cm})$ within each plot. Any 
other burrowing species and invertebrates (i.e. ribbed mussels, Geukensia demissa) were also recorded.

Soil strength was measured in each plot using a shear vane placed in the center of the plot to a depth of $10 \mathrm{~cm}$. Because inundation period can also affect sediment deposition, and elevation determines inundation period, relative elevation was measured in the form of relative tidal heights between plots using the tide stick method (Smith and Warren 2007). This method is performed by deploying tall garden stakes covered in colored craft glue in each plot. After one tidal cycle, the height at which the glue was washed away was measured, providing the relative tidal height within each plot.

Site characteristics, including sediment availability, and $U c a$ population estimates were also measured. At each site, water samples were collected at points every $10 \mathrm{~m}$ along the 100 -m span of plots $(n=3 /$ point $)$, to assess variation in sediment availability along this range. Water samples were filtered onto $47 \mathrm{~mm}$ glass fiber filters, dried at $60{ }^{\circ} \mathrm{C}$ for forty-eight hours, and weighed to calculate total suspended solids concentration. These filters were muffled in a furnace at $550{ }^{\circ} \mathrm{C}$ for two hours and weighed, to calculate fixed suspended solids concentration. Population estimates of $U c a$ were measured by enumerating burrows within haphazardly tossed $0.0625 \mathrm{~m}^{2}$ quadrats $(\mathrm{n}=10)$.

Statistical Analyses: All statistical analyses were conducted in R (Version 3.3.2., R Core Team, 2016). Data were examined for normality and homoscedasticity. Data that did not meet assumptions were transformed to meet assumptions. Multiple linear regressions 
were conducted to determine the effect of $U c a$ burrow density, site, and their interaction on Spartina biomass (natural log transformed), sedimentation rates (natural log transformed), and soil strength (natural log transformed) at each site. To test for differences in hydroperiod across $U c a$-present and $U c a$-absent plots, I ran a t-test within each site. Within site comparisons were made because hydroperiod depends on tidal height, which changes daily, and measurements across sites were not made on the same day.

\section{Effect of Sesarma on sediment deposition}

Plot setup: To study the effect of Sesarma on sedimentation through their grazing of Spartina, another set of $0.0625 \mathrm{~m}^{2}$ plots were set up in three areas, representing a range of grazing intensities: denuded of vegetation (completely grazed), significant grazing (few stems, with shredded and clipped edges [Crichton 1960]), and no grazing ( $\mathrm{n}=8 /$ area) (Figure 3). This study was performed in the same five sites as the field survey for Uca (Figure 2, Table 1).

Measurements: Sedimentation, Spartina production, soil strength, and elevation were measured following the same methods described above. I controlled for distance from the marsh edge (Table 2), similar to the $U c a$ field survey. Additionally, crab burrows were enumerated within each plot, to measure the suitability of each area type for $U c a$. Uca burrows were distinguished from Sesarma burrows by their smaller size and the lack of a hood over the top of the burrow (Seiple and Salmon 1982). 
Statistical Analyses: All statistical analyses were conducted in R software (Version 3.3.2., R Core Team, 2016). All data were examined for normality and homoscedasticity assumptions. Data that did not meet the criteria was transformed to meet assumptions. I conducted fixed effects analysis of variance tests (ANOVAs) to determine the effect of Sesarma grazing intensity, site, and their interaction on the following responses: sedimentation (natural log transformed), soil strength (natural log transformed), and Uca burrow density. The lsmeans function in the lsmeans package (Lenth 2016), with a Tukey correction for p-values was used as a post-hoc test to determine where differences occurred among treatments and among sites. To test the difference in hydroperiod across sampled plots, I conducted an ANOVA within each site. Sites were analyzed separately because hydroperiod varies with tidal height, which differs across days, and sites were not measured on the same day.

\section{Effects of $U c a$ and Sesarma on above- and belowground components of vertical accretion}

To determine the effect of Uca and Sesarma on above- and belowground components of vertical accretion, a caging experiment was conducted at Cushman's Landing, Cape Charles, Virginia USA (Figure 2, Table 1). For logistical purposes, this site was chosen instead of one of the previous survey sites. Creating cage structures is costly and timeintensive, so to accompany the field surveys, I performed the field experiment at only one site. To create the cage structures, a large area of marsh was needed. Boxtree Marsh and Lower Phillips Creek sites featured many long-term monitoring transects, making it unusable. Additionally, cage structures attract Sesarma (Marc Hensel, personal 
communication), so to prevent Sesarma intrusion into cages I used a site with evidence of lower Sesarma populations. Thus, Boxtree Marsh, Lower Phillips, and Wellfleet, were not ideal sites because of high Sesarma grazing rates, evidenced by large denuded, burrow-riddled areas. Finally, cage maintenance was performed bi-weekly, so the site needed to be in Virginia, rather than one of the New England Sites (Prudence Island or Wellfleet). Goodwin Island can only be accessed by boat, making it less accessible. Therefore, Cushman's Landing was chosen as the ideal experimental site (Figure 2, Table $1)$.

Treatments: The field manipulation employed a fully factorial design with four treatments: Uca only, Sesarma only, Uca and Sesarma, and no crabs, with five replicates per treatment. Uncaged reference plots were also deployed. Cages $\left(0.25 \mathrm{~m}^{2}\right)$ were constructed of PVC poles and vinyl-coated wire mesh $(0.635 \mathrm{~cm})$ in the intermediate Spartina zone and dug $15 \mathrm{~cm}$ into the sediment. To prevent crab escape or entrance, the top $10 \mathrm{~cm}$ of cages were lined with aluminum flashing, which crabs are not able to pass (Silliman and Zieman 2001; Holdredge et al. 2010; Gittman and Keller 2013). Cages were arranged in a blocked design with five blocks, with one cage of each treatment placed at least $1 \mathrm{~m}$ apart from each other and at the same distance from the creek edge. Densities and sex ratio of crabs for treatments were determined using population estimates at the site, corresponding to $80 \mathrm{crabs} \mathrm{m}^{-2}$. For the $U c a$ only treatment, 15 adult male and 5 adult female $U c a$ were added to the cages. For the Sesarma only treatment, 2 adult Sesarma were added to the cages. For the Uca and Sesarma treatment, 14 adult male $U c a, 5$ adult female $U c a$, and 1 Sesarma were added to the cages. For control cages, 
a pit trap $(7.5 \mathrm{~cm}$ diameter, $21 \mathrm{~cm}$ deep) was deployed in each to capture any crabs that were not removed upon cage setup (Thomas and Blum 2010). Crabs that were smaller than the wire mesh ( $<6 \mathrm{~mm}$ carapace width) could move freely in and out of the cages, but because these are juveniles with very small or no burrows, I assume their effects are negligible. Crabs were caged from May 032017 - July 29 2017, and checked bi-weekly to ensure crabs were not escaping or intruding. Cages were removed July 29 2017, prior to the taking of measurements, which occurred on August 9-10 2017.

Measurements: In each cage, aboveground Spartina biomass, sedimentation, soil strength, and relative tidal heights were measured following the same methods as the Uca and Sesarma surveys. For this experiment, sediment plates (2 plates per cage) were deployed for nine days, after cage structures were removed. In $45 \%$ of the filters, portions were missing after 9 days, likely due to the power of incoming tides. To keep these observations in analyses, digital images were taken of each filter and analyzed in imageJ (Schneider et al. 2012) to estimate the area of the filter missing, and more accurately calculate sedimentation rate. Any filters that were missing over $50 \%$ of their area were not included in analyses.

Additional measurements in this experiment included: aboveground production, root production, decomposition, belowground biomass, sediment characteristics, and root-toshoot ratio. Aboveground production was measured by comparing final live plant biomass to estimated initial live plant biomass within a $0.0625 \mathrm{~m}^{2}$ sub-section of the caged area. Initial live plant biomass was estimated by measuring the heights of all live 
shoots within the sub-section and using a site-specific allometric equation of shoot height vs. biomass (Equation 2). Aboveground production was calculated as the difference in live biomass between the beginning and end of the experiment, divided by the time the experiment ran.

$$
\text { Estimated shoot biomass }=0.17 * \mathrm{e}^{\text {shoot height*0.04 }}
$$

Equation 2

Root production was measured by deploying a $5.08 \mathrm{~cm}$ wide x $25 \mathrm{~cm}$ long root ingrowth bag constructed of polypropylene produce bags filled with $75 \mathrm{~g}$ of dried peat moss, in each cage at the beginning of the experiment. Root ingrowth bags were removed at the end of the experiment and the contents of bags were rinsed through a $1 \mathrm{~mm}$ mesh sieve within twenty days of retrieval. Roots grown into the bag were then dried at $60{ }^{\circ} \mathrm{C}$ to a constant mass and weighed.

Decomposition was measured by deploying a bag ( $\mathrm{n}=1 /$ cage) constructed of $5 \mu \mathrm{m}$ nitex mesh and filled with $2.5 \mathrm{~g}$ of dried and homogenized Spartina roots and rhizomes $5 \mathrm{~cm}$ beneath the marsh surface, at the beginning of the experiment. At the end of the experiment, bags were pulled from the ground. To ensure no dirt entered the bags, remaining contents of bags were rinsed through a $500 \mu \mathrm{m}$ sieve. After rinsing, remaining root matter was dried at $60{ }^{\circ} \mathrm{C}$ to a constant mass and weighed. Decomposition was calculated as the percent of mass lost over the course of the experiment.

Belowground Spartina biomass was measured by taking a $7.62 \mathrm{~cm}$ diameter core to a depth of $30 \mathrm{~cm}$ around a single shoot of the biomass sub-section of each cage. Cores were 
sectioned into the following increments: $0-5 \mathrm{~cm}, 5-10 \mathrm{~cm}, 10-20 \mathrm{~cm}, 20-30 \mathrm{~cm}$, to create a depth profile. A smaller core $(2.5 \mathrm{~cm}$ wide, $5 \mathrm{~cm}$ long) was taken from each depth increment to measure sediment characteristics. The remainder of the cores were rinsed through stacked sieves $(6 \mathrm{~mm}, 1 \mathrm{~mm})$ to remove any dirt. Roots and rhizomes were separated live, from dead then dried at $60{ }^{\circ} \mathrm{C}$ to a constant mass and weighed.

I measured the following soil characteristics, using the smaller cores removed from the belowground biomass core: water content, bulk density, and loss on ignition (LOI). Small cores were removed from the larger core and weighed wet. Small cores were then dried at $60{ }^{\circ} \mathrm{C}$ to a constant mass and weighed. Finally, small cores were combusted in a muffle furnace at $550{ }^{\circ} \mathrm{C}$ for 16 hours.

Root-to-shoot ratio was measured by summing the live root/rhizome mass from all depths of the belowground biomass cores and comparing it to the shoot biomass, from which the core was taken around. The ratio was calculated by dividing the shoot biomass by the root biomass. Values greater than 1 indicate more shoot than roots, values less than 1 indicate more roots than shoot.

Statistical Analyses: All statistical analyses were conducted in R (Version 3.3.2., R Core Team, 2016). All data were examined for normality and homoscedasticity prior to analysis. Mixed effects ANOVAs, using the nlme package (Pinheiro et al. 2017) were performed to determine the effect of treatment, with block as a random effect, on the following responses: live aboveground biomass, aboveground production, sedimentation 
(natural log transformed), decomposition (measured as percent loss), soil strength (natural log transformed), and belowground production (natural log transformed). The multcomp package (Hothorn et al. 2008), was used for post-hoc analysis. Responses that were measured across depth were analyzed with mixed effects ANOVAs with treatment and depth as fixed effects, and block as a random effect. The following responses were measured across depth: live belowground biomass (natural $\log +0.01$ transformed), percent water of soil (arcsine square root transformed) and percent organic of soil (arcsine square root transformed). Two cages were excluded from all analyses, due to lack of cage effectiveness. 


\section{RESULTS}

\section{Effect of Uca on Spartina alterniflora production and sediment deposition}

Uca density and site interacted to affect Spartina biomass $(\mathrm{P}=0.006$, Figure 4), indicating that there is a site-specific response to Uca burrows. At Goodwin Island and Phillips Creek, plant biomass (natural log transformed) increased linearly with Uca burrows (Goodwin Island: slope $=0.0082, \mathrm{P}=0.01$; Phillips Creek: slope $=0.0049, \mathrm{P}=$ 0.025; Figure 4). At Boxtree and Wellfleet, there was no relationship between plant biomass and $U c a$ burrow density (Boxtree: slope $=0.0014, \mathrm{P}=0.56$; Wellfleet: slope $=$ 0.0011, P = 0.54; Figure 4). Finally, at Prudence Island, Spartina biomass decreased linearly with $U c a$ burrow density (slope $=-0.0056, \mathrm{P}=0.024$, Figure 4).

There was no difference in hydroperiod between plots with and without $U c a$ burrows, except at Boxtree Marsh, where hydroperiod was greater in Uca absent plots (Table 3). There was no relationship between $U c a$ density and sedimentation rates $(\mathrm{P}=0.98$, Figure 5), even at sites where plant biomass increased with $U c a$ density (Goodwin Island and Phillips Creek). Site significantly affected sedimentation rates $(\mathrm{P}=<<0.001$; Figure 5). There was no relationship between $U c a$ density and soil strength $(\mathrm{P}=0.32$, Figure 5), but a significant effect of site $(\mathrm{P}<<0.001$, Figure 6$)$.

\section{Effect of Sesarma on sediment deposition}

There was no difference in hydroperiod across grazing intensity plots, except at Prudence Island, where hydroperiod was lower in the no grazing plots than the denuded and grazed plots (Table 5). I found a significant interaction between grazing intensity and site when 
modeling sedimentation $(\mathrm{P}<<0.001)$. This interaction indicates that the difference in sedimentation rates between grazing intensities, depends on the site. Based on results of post-hoc analysis, mean sedimentation rates at Lower Phillips and Wellfleet were higher in completely grazed areas than areas with no grazing (Figure 7A), contrary to my hypothesis. Prudence Island showed a similar, but non-significant trend, while Boxtree Marsh and Goodwin Island, showed no difference in mean sedimentation rates within the respective site (Figure 7A).

Sesarma grazing intensity also interacted with site to influence belowground soil strength $(\mathrm{P}=0.0018$; Figure 7B). At Lower Phillips and Prudence Island, mean soil strength was lower in areas completely grazed than in areas with no grazing (Figure 7B). A similar, non-significant, trend exits at Wellfleet (Figure 7B). However, at Boxtree Marsh, grazing intensity had no effect on mean soil strength (Figure 7B).

Mean Uca burrow density was significantly affected by Sesarma grazing intensity $(\mathrm{P}=$ 0.044; Figure 8) and site $(\mathrm{P}<<0.001$; Table 4$)$, while their interaction had no effect $(\mathrm{P}=$ 0.59). Mean burrow densities were higher in areas denuded of vegetation than areas with no grazing $(\mathrm{P}=0.034$, Figure 8$)$.

\section{Effects of Uca and Sesarma on above- and belowground components of vertical accretion}

Across all responses, there was no difference between control and reference cages, indicating no significant effect of a cage structure on measured responses. There was a 
significant effect of crab treatment on live aboveground Spartina biomass $(\mathrm{P}=0.002$, Figure 9A). Using a Tukey's Honest Significant Difference Test, I found that live aboveground Spartina biomass was lower in the Sesarma only treatment, than all other treatments (Figure 9A). Additionally, aboveground Spartina production was reduced in the Sesarma only treatment, compared to other treatments $(\mathrm{P}=0.003$, Figure 9B).

Nine sediment plates were removed from analysis due to missing $>50 \%$ of the original filter area through tidal action. Although aboveground biomass was affected by treatment, there was no effect on sedimentation rates $(\mathrm{P}>0.05$, Figure 10).

I found a significant effect of treatment $(\mathrm{P}=0.01)$ and depth $(\mathrm{P}<0.0001)$ on live belowground biomass such that the Sesarma only treatment had lower live belowground biomass than the $U c a$ only and reference treatments (Figure 11A). However, crab treatment did not affect soil characteristics: water content $(\mathrm{P}>0.05$, Figure 11B), bulk density $(\mathrm{P}>0.05$, Figure 11C), or percent organic content $(\mathrm{P}>0.05$, Figure 11D). Additionally, treatment had no effect on soil strength $(\mathrm{P}>0.05$, Figure 12B).

Treatment had no effect on Spartina root-to-shoot ratio $(\mathrm{P}>0.05$, Figure 12A), indicating there was no difference in allocation of resources, in response to crabs. Finally, treatment had no effect on root production $(\mathrm{P}>0.05$, Figure 13A) or decomposition $(\mathrm{P}>0.05$, Figure 13B). 


\section{DISCUSSION}

Ecogeomorphic theory emphasizes the importance of plants in promoting marsh persistence as sea level rises through vertical accretion (Friedrichs and Perry 2001;

Morris et al. 2002; Fagherazzi et al. 2013a). In this study, I demonstrate that animals can impact components of vertical accretion, and in turn, may influence the ability of salt marshes to keep pace with accelerated sea-level rise through their interactions with plants and each other. At some sites, $U c a$ facilitated Spartina growth, but not enough to enhance sedimentation rates. $U c a$ had no effect on belowground components of vertical accretion (e.g. decomposition, organic matter contribution). Sesarma grazing of Spartina increased Uca burrowing and decreased soil strength and belowground organic matter contribution. Uca ameliorated the negative impacts of Sesarma on aboveground plant biomass, but only at low rates of Sesarma grazing. When Sesarma grazing intensity was high, Uca bioturbation likely increased marsh erosion. These results suggest that Sesarma and Uca have a density-dependent impact on components of vertical accretion, and thus their relative population size may influence the ability of salt marshes to keep pace with sealevel rise.

Uca did not significantly impact the above- and belowground components of salt marsh vertical accretion. Facilitation of aboveground Spartina by Uca has been demonstrated in many marshes (Bertness 1985; Thomas and Blum 2010; Gittman and Keller 2013), and my results provide some support for this process. However, I found a site-specific response of Spartina to Uca burrows, as significant changes in plant production were detected in two of the five sites. This indicates that site characteristics may mediate the 
response of plants to $U c a$ burrowing. For example, nutrient-limited short-form Spartina responds more strongly to fiddler crabs than does the non-limited tall-form (Bertness 1985). A similar pattern is seen in fertilization studies of Spartina (Morris et al. 2013, Johnson et al. 2016). Thus, site specificity of the response of Spartina production to Uca burrowing may be due, in part, to nutrient availability. Additionally, controlling for distance from the marsh edge made it difficult to target specific $U c a$ burrow densities, resulting in low replication at many densities. Higher replication may have resulted in significant relationships between $U c a$ burrows and plant biomass at more sites. Because the relationship between $U c a$ and aboveground plant biomass was density-dependent, the lack of significant increases in Spartina biomass in the manipulative experiment may be due to choosing a mean $U c a$ density.

At sites where $U c a$ facilitated Spartina growth, there was no change in sediment deposition. These results appear to contradict the predictions of marsh ecogeomorphic models, as sediment deposition should increase with plant biomass. Morris et al. 2002 found that a $320 \%$ increase in Spartina biomass enhanced vertical by $156 \%$. In my experiment, Uca facilitated Spartina by $230 \%$ and $173 \%$ at two sites, but there was no change in sediment deposition. This lack of influence on sediment deposition rates is likely due to measuring sedimentation for a short period of time. Morris et al. (2002) measured accretion and sediment deposition after 1.5 years with surface elevation tables, but in the present study sedimentation was only measured after one week with sediment plates. Because $U c a$ can freely move in and out of the plots during the measurement period, measuring sedimentation for a longer period of time would have resulted in 
inaccurate estimates of $U c a$ density within the plot. Therefore, although $U c a$ promoted Spartina growth on a similar scale as other studies, this study was not able to capture a similar effect on sediment deposition. However, with time, ecogeomorphic theory suggests that $U c a$ should have a positive density-dependent influence on sedimentation.

In addition to having no significant impacts on the aboveground component of vertical accretion (i.e. sediment deposition), $U c a$ had no effect on belowground components of vertical accretion. One such component is belowground organic matter contribution by plants. The continued existence of belowground organic matter is critical to maintaining elevation. Uca burrowing can accelerate decomposition belowground organic matter as burrows can bring oxygen beneath the marsh surface (Thomas and Blum 2010). In the current study, Uca had no effect on decomposition. While burrows may increase oxygen penetration belowground, this change is extremely localized, occurring only within $2 \mathrm{~mm}$ of burrows (Michaels and Zieman 2013). Thus, I was unable to capture the effect of $U c a$ burrowing on decomposition, because crabs didn't burrow within $2 \mathrm{~mm}$ of the decomposition bags. In addition to the continued existence of belowground organic matter, root production is an important component of vertical accretion. Although other researchers have found a negative relationship between $U c a$ and root production because of increasing nutrient access and shifting plant allocation of resources aboveground (Bertness 1985; Holdredge et al 2010; Thomas and Blum 2010), I found no such effect. Neither root production nor standing stock belowground root biomass was influenced by $U c a$. Because $U c a$ had no impacts on above- or belowground components of vertical 
accretion, this study indicates that they may not have a significant impact on vertical accretion, in isolation.

While Uca may have no effect on vertical accretion in isolation, Sesarma can have significant negative impacts on both above- and belowground components of vertical accretion. Sesarma grazing drastically reduced aboveground plant biomass (Figures 9A \& 9B; Holdredge et al. 2009). Although a subsequent decrease in sediment deposition was expected, the opposite was detected in this study. In areas completely grazed by Sesarma, sedimentation rates were higher than anywhere else measured (Figure 7A). This is counter to the predictions of ecogeomorphic models of saltmarsh accretion, which demonstrate a positive relationship between plant biomass and sedimentation (Friedrichs and Perry 2001, Morris et al. 2002, Fagherazzi et al. 2013a). One explanation for this trend may be that a portion of the inorganic sediment deposited in these areas is resuspended from the marsh surface, not delivered by the tides. The relationship between marsh plant biomass and sediment deposition only accounts for sediment coming in with the flooding water, not sediment that is resuspended off the marsh surface. Thus, our measurements of sedimentation in areas grazed by Sesarma may be confounded by marsh surface sediments. In areas denuded of vegetation, soil strength was much weaker than vegetated areas (Figure 7B), suggesting greater potential for surface sediments to be resuspended by tidal scour and deposited onto the plates used to measure sedimentation (Fagherazzi et al. 2013b). 
Another potential explanation for these counter-intuitive results is bioturbation by $U c a$ (Figure 14). Sesarma grazing, which results in large areas of grass die-back, facilitates the establishment of high densities of $U c a$ in these unvegetated areas (Smith 2015, Figure 8). Without vegetation, the soil is weaker, making it easier for $U c a$ to burrow (Bertness and Miller 1984) and creating preferable habitat (Smith 2015). Across the survey sites, Uca burrow densities were higher in the areas denuded of vegetation (Figure 8). Furthermore, $U c a$ burrowing activities can cause suspension of sediment from the marsh surface (Smith and Green 2015), which supports the idea that sediment measured on the sediment plates was from the marsh surface, not the water column. Additionally, higher Uca burrow densities combined with weaker soil strength in areas grazed down by Sesarma, may have resulted in crabs excavating their burrows directly onto sediment plates, further confounding our measurements of sedimentation rates. Therefore, while Uca may have an indirect accretive effect on marsh geomorphology in isolation, in areas of high Sesarma grazing, it may instead have an erosional effect.

Sesarma also negatively influenced belowground components of vertical accretion. Sesarma grazing reduced belowground biomass (Figure 11A), similar to other studies (Coverdale et al. 2012). Through continued reduction of belowground biomass, Sesarma grazing can decrease contribution of belowground organic matter. However, Sesarma had no effect on root production in this study. In the manipulative experiment, root production measured plant allocation of resources towards belowground growth, because crabs could not access roots in the ingrowth bags. Similarly, based on root-to-shoot ratio, there's further evidence that Sesarma grazing doesn't influence allocation of resources 
towards above- or belowground growth. When plants are grazed, two defense strategies can be utilized: overproduction of biomass or chemical defense (Herms and Mattson 1992). Sesarma negatively impacted aboveground Spartina production and had no impact on belowground production, which indicates that plants are instead investing in chemical defenses, rather than producing more biomass. However, Sesarma did reduce belowground biomass, based on analysis of cores. Consumption of roots over longer periods, combined with plants investing in chemical defense over biomass production, could lead to an overall decrease in organic matter accumulation through continued reduction in standing stock of belowground biomass.

Sesarma also reduced soil strength, which poses a threat to marsh stability. Edge erosion is a major source of marsh loss and contraction (Mariotti and Fagherazzi 2010; Tonelli et al. 2010; Fagherazzi et al. 2013b). At four of the five survey sites, the areas denuded of vegetation existed at the marsh edge, spanning a distance up to $3 \mathrm{~m}$ wide. With low soil strength in these areas via Sesarma grazing belowground, surface sediments are more susceptible to erosion (van Eerdt 1985; Fagherazzi et al. 2013b; Vu et al. 2017). Erodibility is further enhanced with high densities of $U c a$ burrows, which weaken the sediments even more through bioturbation and resuspension, and can ultimately lead to elevation loss (Escapa et al. 2008; Smith and Green 2015). The results of this study suggest Sesarma grazing can negatively impact marsh persistence in the face of sea-level rise by promoting edge erosion, and reducing above- and belowground Spartina biomass. 
The combined effects of Sesarma and Uca are dependent on the relative level of activity of each species (e.g. high vs. low grazing by Sesarma, high vs. low bioturbation by Uca). When Sesarma grazing intensity is high, the positive effects of Uca on plant production are masked. Sesarma grazing led to increased burrow densities (Figure 8; Smith 2015). In these large denuded areas, Uca can prevent Spartina seedling establishment, and ultimately plant recolonization of denuded areas (Smith and Tyrell 2012). Thus, high levels of Sesarma grazing combined with Uca burrowing, may have prolonged negative effects on salt marsh persistence with sea-level rise, by removing vegetation and indirectly preventing its recolonization. Additionally, Uca burrowing in these unvegetated areas can lead to sediment resuspension and subsequent elevation loss (Smith and Green 2015). Therefore, positive effects of $U c a$ on aboveground Spartina biomass are masked when a cascade of events via intense Sesarma grazing occurs, resulting in $U c a$-induced erosion. Ultimately, $U c a$, which can positively influence salt marshes by facilitating primary production, can also have negative impacts on salt marsh persistence with sea-level rise depending on the intensity of Sesarma grazing.

However, when $U c a$ exists when Sesarma grazing intensity is low, Uca may ameliorate the negative impacts of Sesarma grazing by facilitating aboveground Spartina growth. In the cage experiment, aboveground plant biomass was higher when Uca and Sesarma were caged together than when Sesarma was by itself (Figure 9A), suggesting that the facilitative effects of $U c a$ may mitigate the negative impacts of Sesarma grazing aboveground. Uca ameliorates the stress of other Spartina grazers (Gittman and Keller 2013), and the results of this study suggest they may do the same with Sesarma. 
Therefore, marshes with low Sesarma grazing intensity, may be better equipped to respond positively to sea-level rise than marshes with high Sesarma grazing intensity.

\section{Conclusions}

The continued provision of ecosystem services by salt marshes relies on their ability to keep pace with accelerated sea-level rise through vertical and lateral movements (Barbier et al. 2011; Kirwan and Megonigal 2013; Weston 2014; Kirwan et al. 2016). While the importance of marsh plants, such as Spartina, in promoting marsh stability and accretion have long been demonstrated (Morris et al. 2002; Friedrichs and Perry 2001; Fagherazzi et al. 2013a; Fagherazzi et al. 2013b), I show that animals can indirectly influence geomorphic processes, through their interactions with marsh plants. While facilitation of plant production by Uca isn't enough to cause geomorphic change, based on the results of this study, herbivory by Sesarma can have extremely negative impacts on marsh persistence as sea-level rises, through increased erosion susceptibility and reduced contribution of roots belowground. However, $U c a$ may counter the negative impacts of Sesarma, when Sesarma populations are low. Alternatively, when Sesarma populations are high, Uca burrowing may accelerate Sesarma-driven elevation loss (Smith and Green 2015) and erosion (Escapa et al. 2008; Fagherazzi et al. 2013b). While the direct impacts of animals on the physical shape of an ecosystem have been well-studied (Jones et al. 1994; Butler 1995; Naiman et al. 1988; Vu et al. 2017), this study demonstrates that their indirect impacts can also be important. Thus, the incorporation of animals and their population estimates into ecogeomorphic models may help produce a more holistic understanding of how salt marshes will respond to a rising sea in a changing climate. 


\section{LITERATURE CITED}

Altieri, A. H., Bertness, M. D., Coverdale, T. C., Herrmann, N. C., and Angelini, C. 2012. A trophic cascade triggers collapse of a salt-marsh ecosystem with intensive recreational fishing. Ecology 93 (6): 1402-1410.

Barbier, E. B., Hacker, S. D., Kennedy, C., Koch, E. W., Stier, A. C., and Silliman, B. R. 2011. The value of estuarine and coastal ecosystem services. Ecological Monographs 81 (2): 169-193.

Bertness, M. D. 1895. Fiddler crab regulation of Spartina alterniflora production on a New England salt marsh. Ecology 66 (3): 1042-1055.

Bertness, M. D. and Miller, T. 1984. The distribution and dynamics of Uca pugnax (Smith) burrows in a New England salt marsh. Journal of Experimental Marine Biology and Ecology 83 (3): 211-237.

Butler, D. R. 1995. Zoogeomorphology: animals as geomorphic agents. Cambridge University Press.

Coverdale, T. C., Altieri, A. H., and Bertness, M. D. 2012. Belowground herbivory increases vulnerability of New England salt marshes to die-off. Ecology 93 (9): 20852094.

Crichton, O. W. 1960. Marsh crab: intertidal tunnel-maker and grass-eater. Estuarine Bulletin 5 (4): 3-10.

Escapa, M., Perillo, G. M., and Iribarne, O. 2008. Sediment dynamics modulated by burrowing crab activities in contrasting SW Atlantic intertidal habitats. Estuarine, Coastal, and Shelf Science 80 (3): 365-373. 
Fagherazzi S., D. M. FitzGerald, R.W. Fulweiler, Z. Hughes, P.L. Wiberg, K.J. McGlathery, J.T. Morris, T.J. Tolhurts, L.A. Deegan, and D.S. Johnson. 2013. Ecogeomorphology of Salt Marshes. Treatise on Geomorphology 12, 182-200. Fagherazzi, S. G., Mariotti, G., Wiberg, P. I., and McGlathery, K. J. 2013. Marsh collapse does not require sea level rise. Oceanography 26 (3): 70-77.

Friedrichs, C.T. and Perry, J. E. 2001. Tidal salt marsh morphodynamics: A synthesis. Journal of Coastal Research Special Issue 27, 7-37.

Gittman, R. K., Fodrie, F. J., Popowich, A. M., Keller, D. A., Bruno, J. F., Currin, C. A., Peterson, C. H., and Piehler, M. F. 2015. Engineering away our natural defenses: an analysis of shoreline hardening in the US. Frontiers in Ecology and the Environment 13 (6): 301-307.

Gittman, R. K. and Keller, D. A. 2013. Fiddler crabs facilitate Spartina alterniflora growth, mitigating periwinkle overgrazing of marsh habitat. Ecology 94 (12): 2709-2718. Grimes, B. H., Huish, M. T., and Kerby, J. H. 1989. Species profiles: life histories and environmental requirements of coastal fishes and invertebrates (mid-Atlantic): Atlantic marsh fiddler. U.S. Fish and Wildlife Service Biological Report 82 (11.114).

Herms, D. A., and Mattson, W. J. 1992. The dilemma of plants: to grow or defend. The Quarterly Review of Biology 67 (3): 283-335.

Holdredge, C., Bertness, M. D., and Altieri, A. H. 2009. Role of crab herbivory in die-off of New England salt marshes. Conservation Biology 23 (3): 672-279.

Holdredge, C., Bertness, M. D., Herrmann, N. C., and Gedan, K. B. 2010. Fiddler crab control of cordgrass primary production in sandy sediments. Marine Ecology Progress Series 399: 253-259. 
Hothorn, T., Bretz, F., and Westfall, P. 2008. Simultaneous Inference in General Parametric Models. Biometrical Journal 50 (3): 346--363.

Hughes, A. R., Moore, A. F. P., and Piehler, M. F. 2014. Independent and interactive effects of two facilitators on their habitat-providing host plant, Spartina alterniflora. Oikos 123 (4): 488-499.

Hughes, Z. J., FitzGerald, D. M., Wilson, C. A., Pennings, S. C., Wieski, K., and Mahadevan, A. 2009. Rapid headward erosion of marsh creeks in response to relative sea level rise. Geophysical Research Letters 36 (3): L03602.

Johnson, D. S. 2014. Fiddler on the roof: a northern range extension for the marsh fiddler crab Uca pugnax. Journal of Crustacean Biology 34 (5): 671-673.

Johnson, D. S., Warren, R. S., Deegan, L. A., and Mozdzer, T. J. 2016 Saltmarsh plant responses to eutrophication. Ecological Applications 26 (8): 2647-2659.

Jones, C. G., J. H. Lawton, and M. Shachak. 1994. Organisms as ecosystem engineers. Oikos 69: 373-386.

Kirwan, M. L and Megonigal, J. P. 2013. Tidal wetland stability in the face of human impacts and sea-level rise. Nature 504 (7478): 53-60.

Kirwan, M. L., Temmerman, S., Skeehan, E., Guntenspergen, G. R., and Fagherazzi, S. 2016. Overestimation of marsh vulnerability to sea level rise. Nature Climate Change 6 (3): $253-260$.

LeMay, L. 2007. The impact of drainage ditches on salt marsh flow patterns, sedimentation and morphology: Rowley River, Massachusetts (Master's Thesis). Virginia Institute of Marine Science. 
Lenth, R. V. 2016. Least-Squares Means: The R Package 1smeans. Journal of Statistical Software, 69 (1), 1-33.

Mariotti, G. and Fagherazzi, S. 2010. A numerical model for the coupled long-term evolution of salt marshes and tidal flats. Journal of Geophysical Research: Earth Surface 115: F01004.

McRaith, B. J., Gardner, L. R., Wethey, D. S., and Moore, W. S. 2003. The effect of fiddler crab burrowing on sediment mixing and radionuclide profiles along a topographic gradient in a southeastern salt marsh. Journal of Marine Research 61: 359-390.

Mendelssohn I.A., Morris J.T. 2002. Eco-Physiological Controls on the Productivity of Spartina Alterniflora Loisel. In: Weinstein M.P., Kreeger D.A. (eds) Concepts and Controversies in Tidal Marsh Ecology. Springer, Dordrecht

Michaels, R. E. and Zieman, J. C. 2013. Fiddler crab (Uca spp.) burrows have little effect on surrounding sediment oxygen concentrations. Journal of Experimental Marine Biology and Ecology 448, 104-113.

Morris, J. T., Sundareshwar, P. V., Nietch, C. T., Kjerfve, Bjorn, and Cahoon, D. R. 2002. Responses of coastal wetlands to rising sea level. Ecology 83 (10): 2869-2877. Morris, J. T., Sundberg, K., and Hopkinson, C. S. 2013. Salt marsh primary production and its responses to relative sea level and nutrients in estuaries at Plum Island, Massachusetts, and North Inlet, South Carolina, USA. Oceanography 26 (3): 78-84. Naiman, R. J., C. A. Johnston, and J. C. Kelley. 1988. Alteration of North American streams by beaver. BioScience 38 (11): 753-762. 
Pinheiro, J., Bates, D., Debroy, S., Sarkar, D., and R Core Team. 2017._nlme: Linear and Nonlinear Mixed Effects Models_. R package version 3.1-131. Retrieved from: https://CRAN.R-project.org/package=nlme>.

Pontee, N. 2013. Defining coastal squeeze: A discussion. Ocean \& Coastal Management 84: 204-207.

Sallenger, A. H. Jr., Doran, K. S., and Howd, P. D. 2012. Hotspot of accelerated sea-level rise on the Atlantic coast of North America. Nature Climate Change 2 (12): 884-888. Schneider, C. A., Rasband, W. S., and Eliceiri, K. W. 2012. NIH Image to ImageJ: 25 years of image analysis. Nature Methods 9 (7), 671-675.

Seiple, W. 1979. Distribution, habitat preferences and breeding periods in the crustaceans Sesarma cinereum and S. reticulatum) Brachyura: Decapoda: Grapsidae). Marine Biology 52 (1): 77-86.

Seiple, W. and Salmon, M. 1982. Comparative social behavior of two grapsid crabs, Sesarma reticulatum (Say) and S. cinereum (Bosc.). Journal of Experimental Marine Biology and Ecology 62 (1): 1-24.

Silliman, B. R., and Zieman, J. C. 2001. Top-down control of Spartina alterniflora production by periwinkle grazing in a Virginia salt marsh. Ecology 82, 2830-2845. Smith, S. M. 2015. Does loss of salt marsh vegetation caused by a native grapsid crab improve habitat suitability for the Atlantic mud fiddler (Uca pugnax)? Journal of Crustacean Biology 35 (5), 616-621.

Smith, S. M. and Green, C. W. 2015. Sediment suspension and elevation loss triggered by Atlantic mud fiddler crab (Uca pugnax) bioturbation in salt marsh dieback areas of southern New England. Journal of Coastal Research 31 (4): 88-94. 
Smith, S. M., and Tyrell, M. C. 2012. Effects of mud fiddler crabs (Uca pugnax) on the recruitment of halophyte seedlings in salt marsh dieback areas of Cape Cod (Massachusetts, USA). Ecological Research 27 (1), 233-237.

Smith, S. M. and Warren, S. 2007. Determining ground surface topography in tidal marshes using watermarks. Journal of Coastal Research 23 (1): 265-269.

Stachowicz, J. J. 2001. Mutlaism, facilitation, and the structure of ecological communities. AIBS Bulletin 51 (3): 235-246.

Thomas, C.R. and Blum, L. K. 2010. Importance of the fiddler crab Uca pugnax to salt marsh soil organic matter accumulation. Marine Ecology Progress Series 414, 167-177. Tonelli, M., S. Fagherazzi, and M. Petti. 2010. Modeling wave impact on salt marsh boundaries. Journal of Geophysical Research 115: C09028.

van Eerdt, M. M. 1985. The influence of vegetation on erosion and accretion in salt marshes of the Oosterschelde, the Netherlands. Vegetatio 62 (1/3): 367-373.

Vu, H. D., Wieski, K., and Pennings, S. C. 2017. Ecosystem engineers drive creek formation in salt marshes. Ecology 98 (1), 162-174.

Weston, N. B. 2014. Declining sediments and rising seas: an unfortunate convergence for tidal wetlands. Estuaries and Coasts 37: 1-23. 


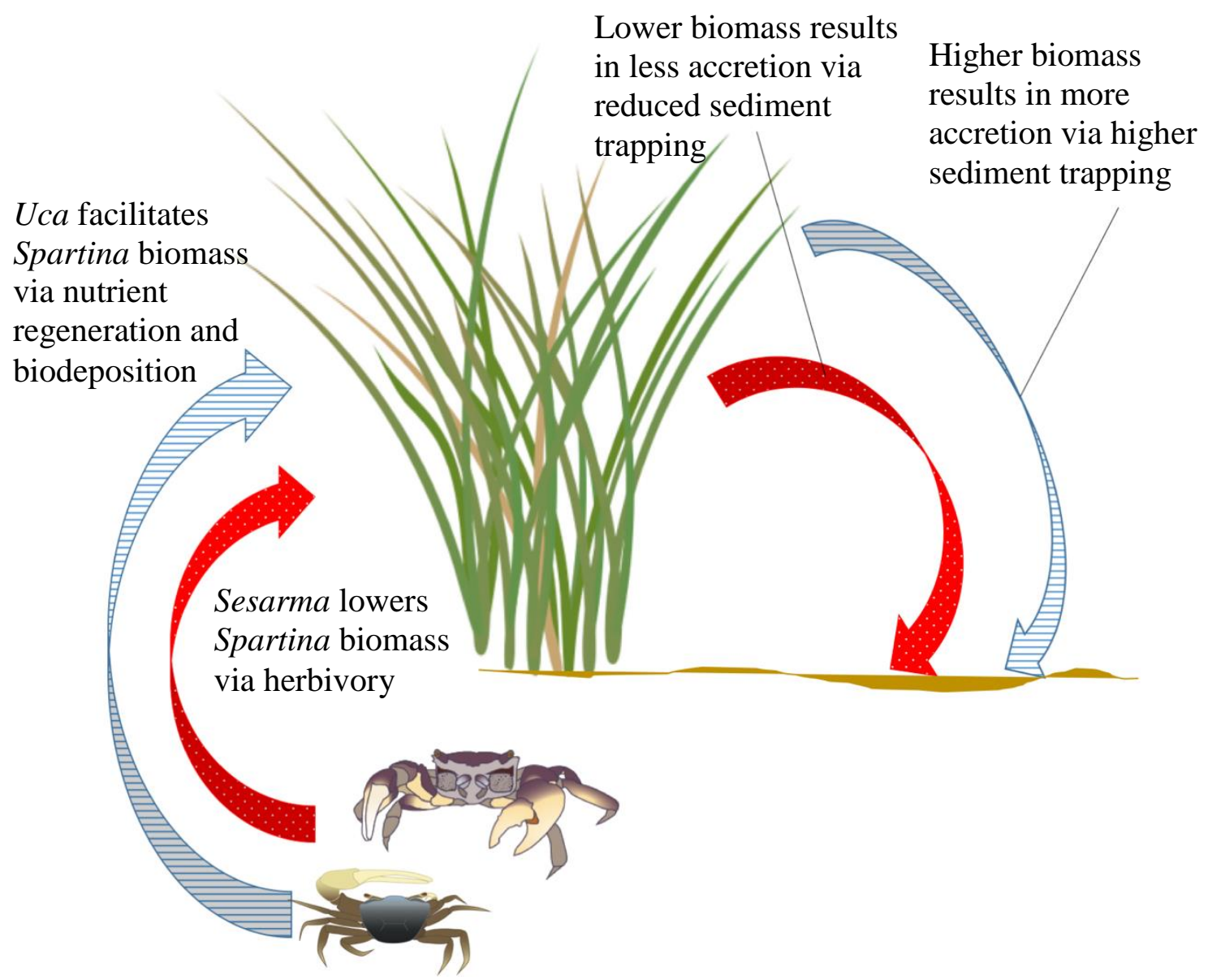

Figure 1: Conceptual diagram for the potential effects of two crustacean species, the marsh fiddler crab (Uca pugnax), and the purple marsh crab (Sesarma reticulatum) on salt marsh geomorphic processes through their interactions with Spartina alterniflora. Images courtesy Tracy Saxby, IAN Image Library and Lauren Huey. 
Table 1: Sites selected for surveys and field manipulation. * indicates site used for field manipulation.

\begin{tabular}{|c|c|c|c|c|}
\hline City, State & Location & $\begin{array}{l}\text { Marsh } \\
\text { Name }\end{array}$ & $\begin{array}{l}\text { Latitude, } \\
\text { Longitude }\end{array}$ & Notes \\
\hline $\begin{array}{l}\text { Wellfleet, } \\
\text { Massachusetts }\end{array}$ & $\begin{array}{l}\text { Cape Cod National } \\
\text { Seashore }\end{array}$ & Gut Marsh & $\begin{array}{l}41.930871 \mathrm{~N} \\
-70.068266 \mathrm{~W}\end{array}$ & National Park \\
\hline $\begin{array}{l}\text { Prudence Island, } \\
\text { Rhode Island }\end{array}$ & Narragansett Bay & Nag Marsh & $\begin{array}{l}41.625476 \mathrm{~N} \\
-71.326034 \mathrm{~W}\end{array}$ & $\begin{array}{l}\text { National Estuarine } \\
\text { Research Reserve }\end{array}$ \\
\hline $\begin{array}{l}\text { Nassawadox, } \\
\text { Virginia }\end{array}$ & $\begin{array}{l}\text { Eastern Shore of } \\
\text { Virginia }\end{array}$ & $\begin{array}{l}\text { Lower } \\
\text { Phillips } \\
\text { Creek }\end{array}$ & $\begin{array}{l}37.453680 \mathrm{~N} \\
-75.835666 \mathrm{~W}\end{array}$ & $\begin{array}{l}\text { Long-Term Ecological } \\
\text { Research Site }\end{array}$ \\
\hline $\begin{array}{l}\text { Machipongo, } \\
\text { Virginia }\end{array}$ & $\begin{array}{l}\text { Eastern Shore of } \\
\text { Virginia }\end{array}$ & $\begin{array}{l}\text { Boxtree } \\
\text { Marsh }\end{array}$ & $\begin{array}{l}37.394436 \mathrm{~N} \\
-75.870237 \mathrm{~W}\end{array}$ & $\begin{array}{l}\text { Long-Term Ecological } \\
\text { Research Site }\end{array}$ \\
\hline Seaford, Virginia & Goodwin Island & & $\begin{array}{l}37.215953 \mathrm{~N} \\
-76.404900 \mathrm{~W}\end{array}$ & $\begin{array}{l}\text { National Estuarine } \\
\text { Research Reserve }\end{array}$ \\
\hline $\begin{array}{l}\text { Cape Charles, } \\
\text { Virginia* }\end{array}$ & Cushman's Landing & & $\begin{array}{l}37.174337 \mathrm{~N} \\
-75.942386 \mathrm{~W}\end{array}$ & $\begin{array}{l}\text { Long-Term Ecological } \\
\text { Research Site }\end{array}$ \\
\hline
\end{tabular}



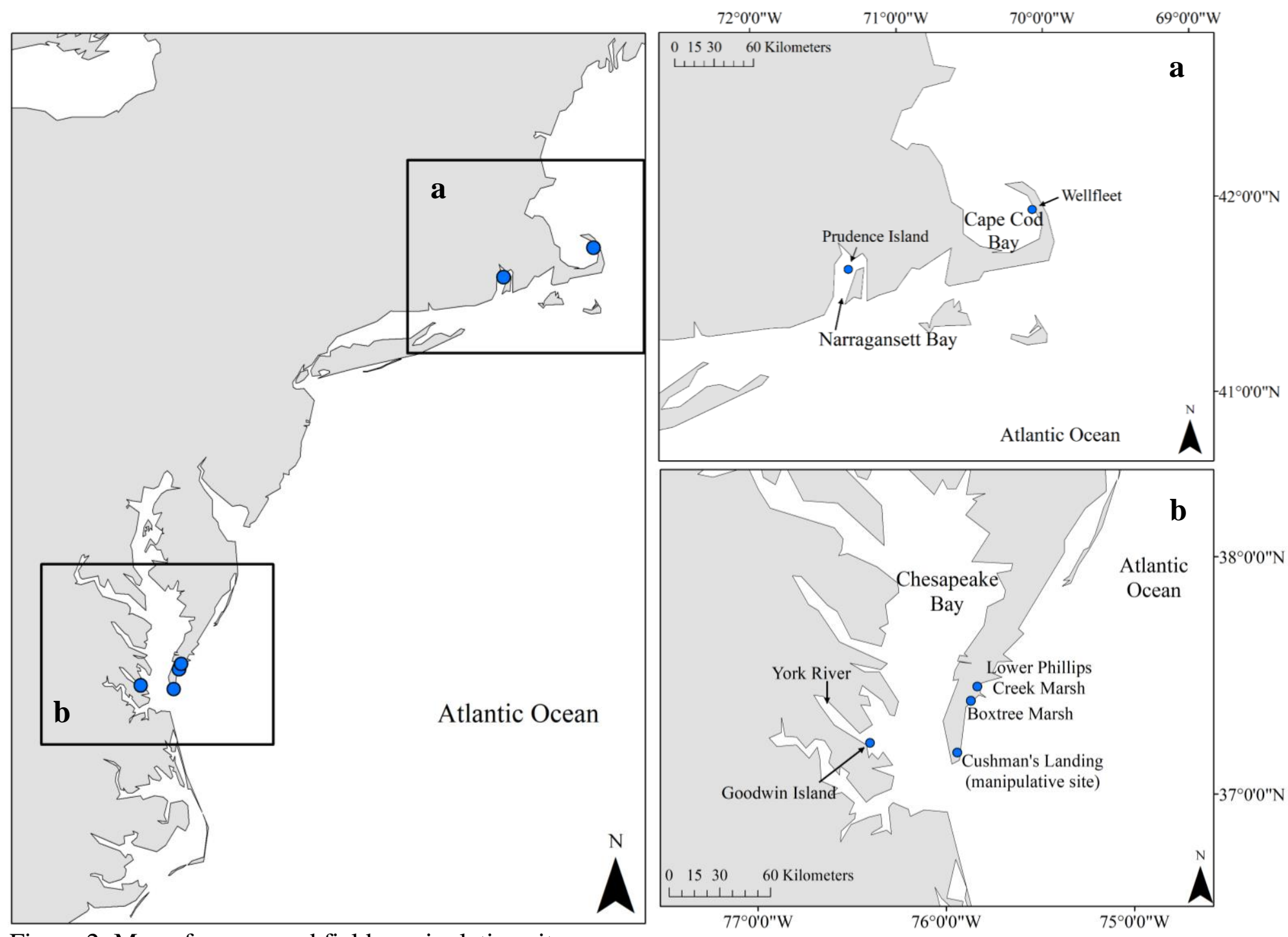

Figure 2: Map of survey and field manipulation sites 


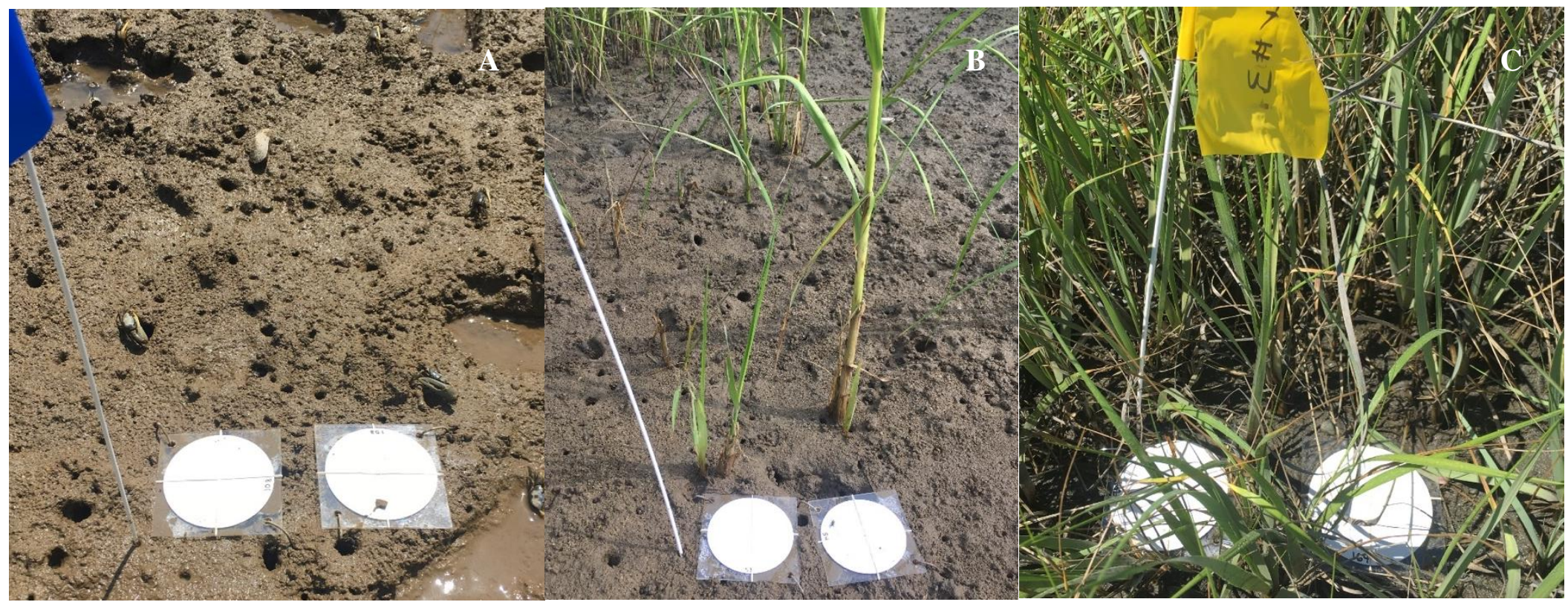

Figure 3: Sesarma grazing intensity plot types. A) denuded B) significantly grazed and C) no grazing. 
Table 2: Site-level characteristics. Mean \pm standard error ( $n$ in parentheses) salinity and fixed suspended solids concentrations across sites in survey and field manipulation. * indicates site used for cage manipulation.

\begin{tabular}{lcccc}
\hline Site & Salinity (ppt) & $\begin{array}{c}\text { Suspended } \\
\text { Solids } \\
\text { Concentration } \\
\left(\mathrm{mg} \mathrm{L}^{-1}\right)\end{array}$ & $\begin{array}{c}\text { Uca plots } \\
\text { distance from } \\
\text { marsh edge }(\mathrm{cm})\end{array}$ & $\begin{array}{c}\text { Sesarma plots } \\
\text { distance from } \\
\text { marsh edge }\end{array}$ \\
\hline \hline Wellfleet & $33.8 \pm 11.3(9)$ & $4.48 \pm 0.4(9)$ & $16.4 \pm 0.6(13)$ & $15.3 \pm 0.6(24)$ \\
Prudence & $33.9 \pm 7.4(21)$ & $3.50 \pm 0.4(21)$ & $3.7 \pm 0.2(16)$ & $2.2 \pm 0.1(24)$ \\
Island & $35.4 \pm 8.4(18)$ & $15.19 \pm 1.1(18)$ & $8.8 \pm 0.1(16)$ & $3.0 \pm 0.1(24)$ \\
Lower & $37.3 \pm 10.8(12)$ & $36.34 \pm 1.2(12)$ & $38.8 \pm 0.1(16)$ & $8.4 \pm 0.0(24)$ \\
Phillips & $20.9 \pm 7.0(9)$ & $15.95 \pm 2.0(9)$ & $9.0 \pm 0.2(16)$ & $0.83 \pm 0.4(24)$ \\
Boxtree & & $102.4 \pm 32.2(15)$ & --- & -- \\
Goodwin & --- & & & \\
Island & & & & \\
Cushman's & & & & \\
Landing* & & & & \\
\hline
\end{tabular}


Table 3: Mean \pm standard error ( $n$ in parentheses) relative tidal heights $(\mathrm{cm})$ across $U c a$ present and absent plots at five survey marshes. Values that share superscripted letters indicate no statistical difference based on ANOVA (P > 0.05).

\begin{tabular}{lccc}
\hline Site & Present & Absent & P-value \\
\hline \hline Boxtree & $39.7 \pm 0.4(8)$ & $42.9 \pm 0.5(8)$ & $\mathbf{0 . 0 1}$ \\
Goodwin Island & $12.0 \pm 1.0(8)$ & $12.3 \pm 0.4(8)$ & 0.69 \\
Lower Phillips & $18.4 \pm 1.0(8)$ & $21.4 \pm 1.0(7)$ & 0.21 \\
Prudence Island & $34.5 \pm 0.8(8)$ & $33.8 \pm 1.0(8)$ & 0.59 \\
Wellfleet & $34.5 \pm 1.9(8)$ & $36.4 \pm 0.5(5)$ & 0.45 \\
\hline
\end{tabular}




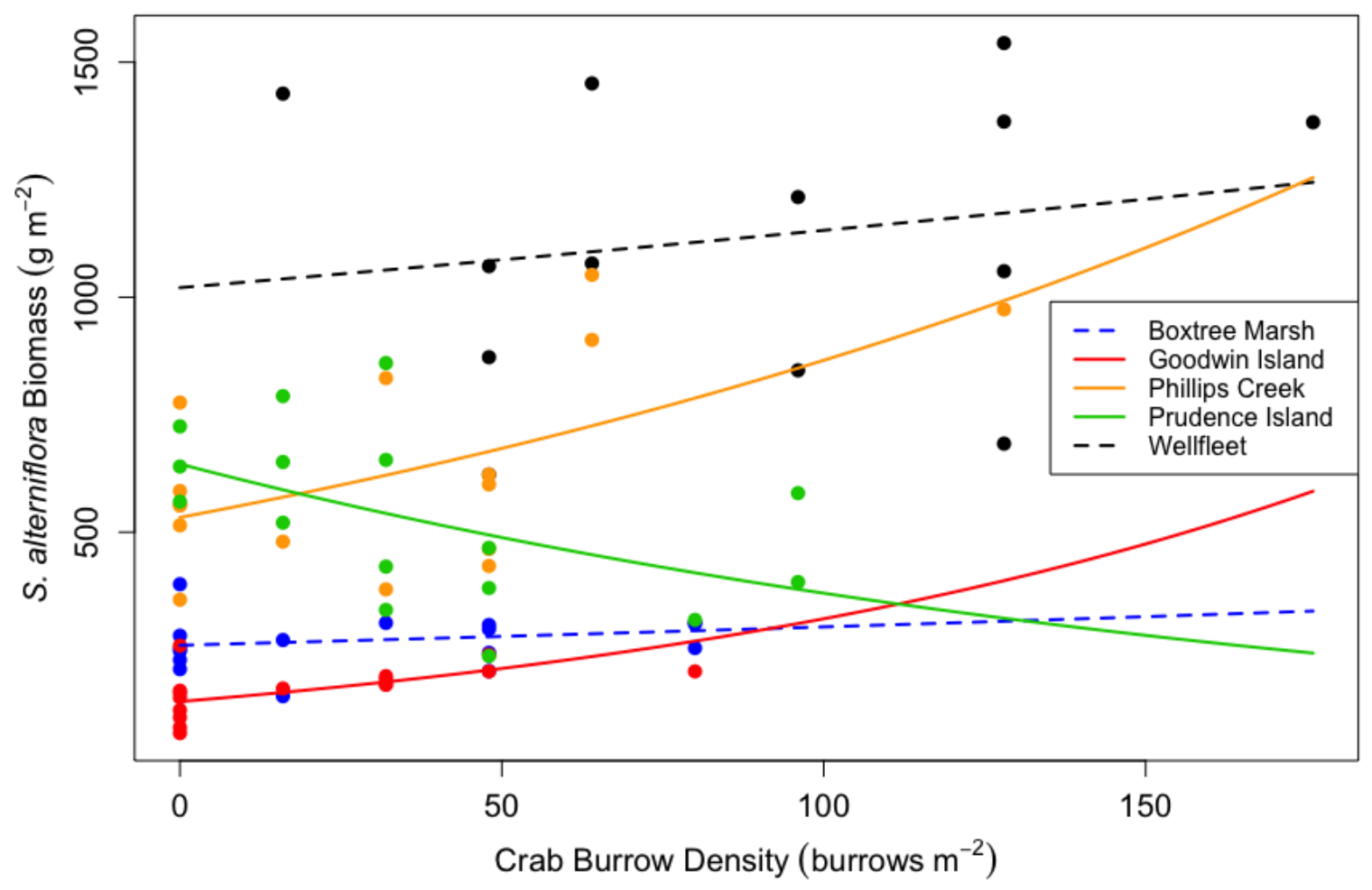

Figure 4: Relationship between Uca burrow density and Spartina biomass across sites. Data displayed is untransformed, but model was applied to log-transformed data. Trendlines are based on back-calculated estimates from model outputs. Solid lines indicate significant linear relationship $(\mathrm{P}<0.05)$; dashed lines non-significant relationships $(\mathrm{P}>0.05)$ based on multiple linear regression. 


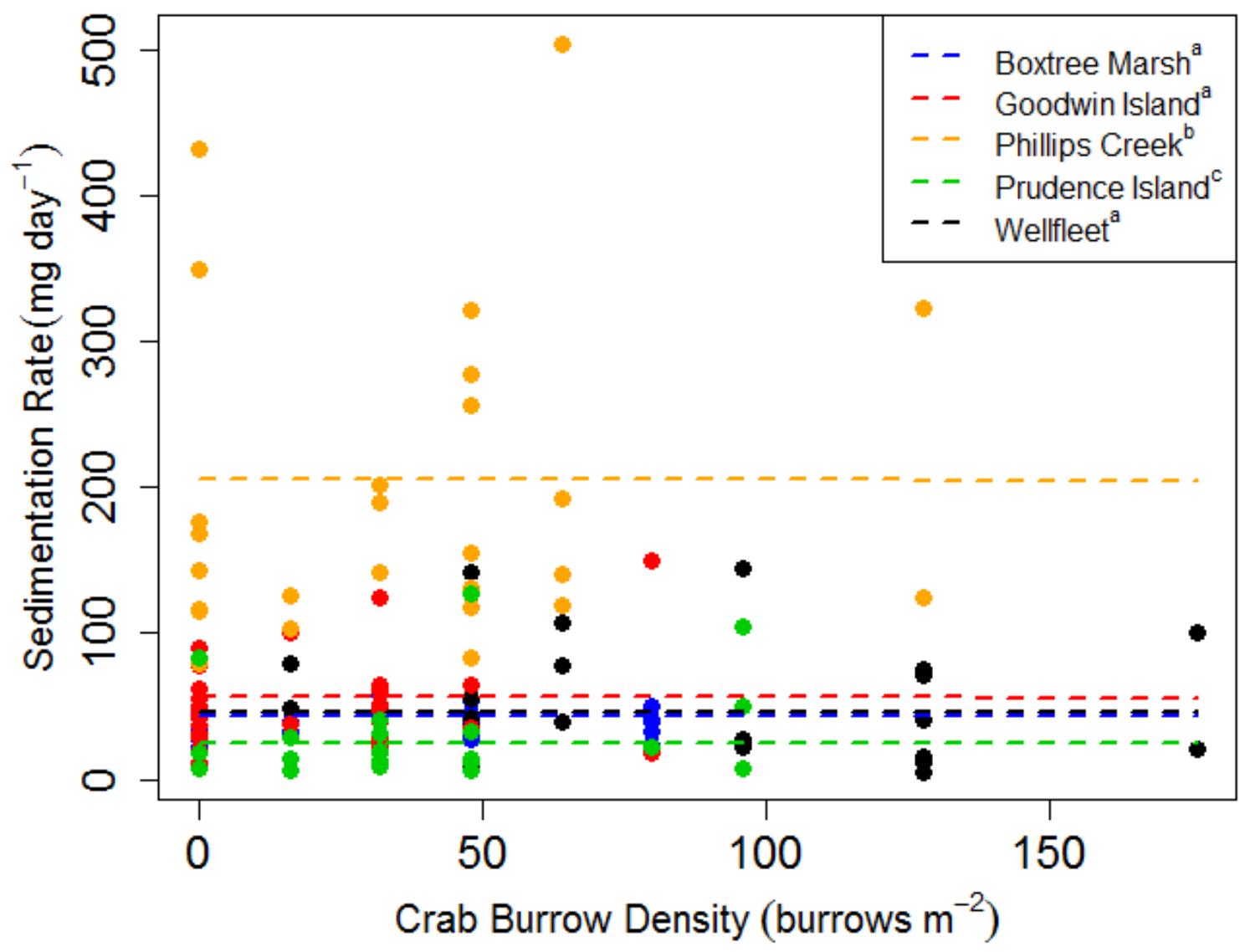

Figure 5. Relationship between $U c a$ burrow density and sedimentation rates across sites. Data displayed is untransformed. Models were run on natural log transformed data. Dashed lines indicate non-significant relationships between burrow density and sedimentation rates $(\mathrm{P}>0.05)$ based on multiple linear regression Sites that share a superscripted letter have similar sedimentation rates. 


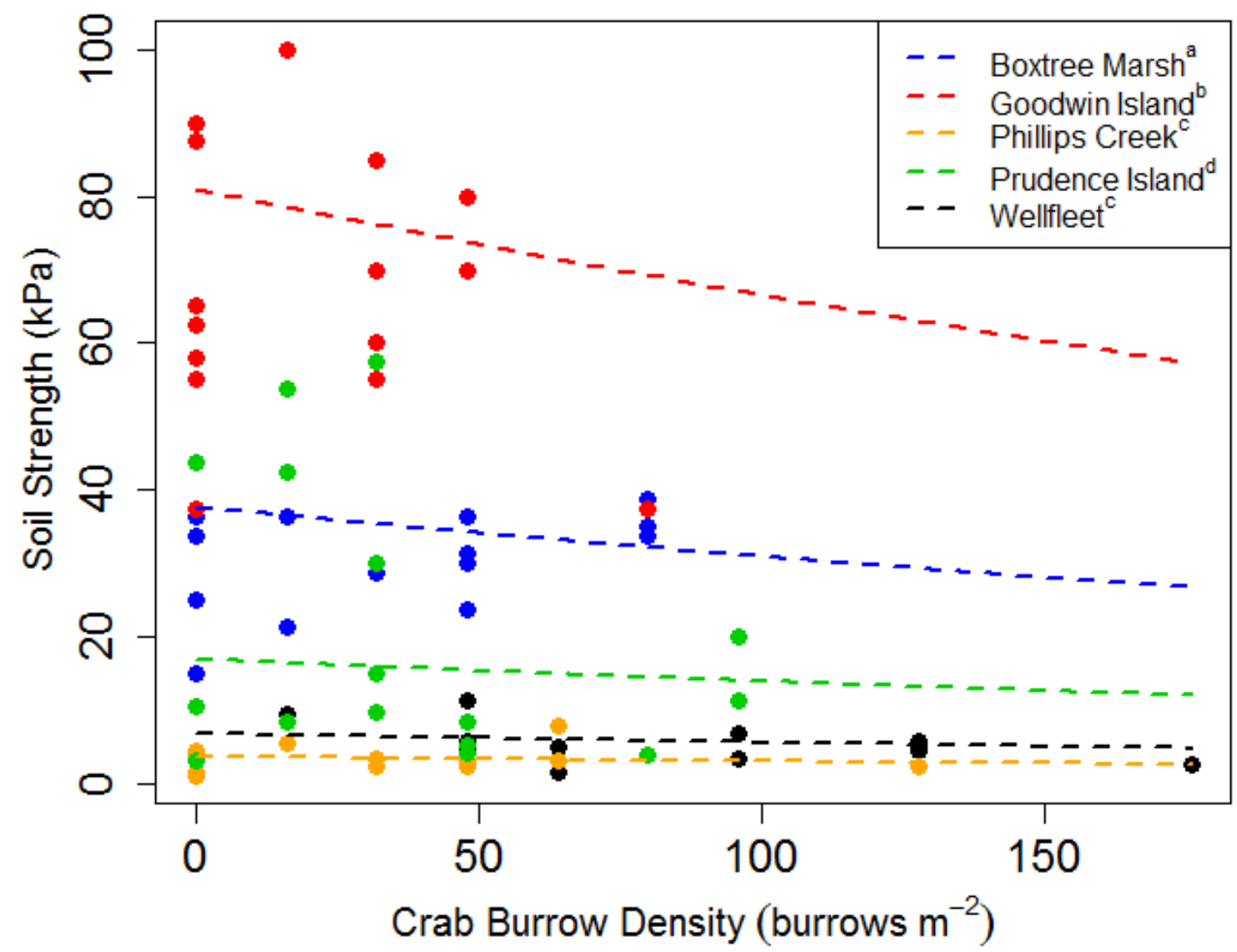

Figure 6. Relationship between soil strength and $U c a$ burrow densities across sites. Data depicted is untransformed while models were run on natural log transformed data. Dashed lines indicate non-significant relationships based on multiple linear regression. Sites that share a superscripted letter indicate no statistical difference. 
Table 4: Mean \pm standard error ( $n$ in parentheses) Spartina biomass $\left(\mathrm{g} \mathrm{m}^{-2}\right)$ across Sesarma grazing intensity and mean $U c a$ burrow density (burrows $\mathrm{m}^{-2}$ ), averaged across grazing intensity, across sites at field survey marshes. Burrow densities that share a superscripted letter indicate no statistical difference through post-hoc analysis $(\mathrm{P}>0.05)$.

\begin{tabular}{lcccc}
\hline Site & Denuded & Grazed & No Grazing & $\begin{array}{c}\text { Uca burrow } \\
\text { density }\end{array}$ \\
\hline \hline Boxtree Marsh & $0 \pm 0(8)$ & $190.5 \pm 29.7(7)$ & $737.8 \pm 59.0(8)$ & $196 \pm 11(24)^{\mathrm{a}}$ \\
Goodwin Island & $0 \pm 0(8)$ & $274.1 \pm 38.8(8)$ & $714.3 \pm 76.8(8)$ & $99 \pm 14(24)^{\mathrm{b}}$ \\
Lower Phillips & $0 \pm 0(8)$ & $332.2 \pm 35.4(8)$ & $620.0 \pm 44.1(8)$ & $106 \pm 9(24)^{\mathrm{bc}}$ \\
Creek & & & & \\
Prudence Island & $0 \pm 0(8)$ & $140.6 \pm 15.3(8)$ & $405.7 \pm 29.2(8)$ & $63 \pm 8(24)^{\mathrm{c}}$ \\
Wellfleet & $0 \pm 0(8)$ & $274.5 \pm 43.0(8)$ & $921.3 \pm 129.1(8)$ & $111 \pm 12(24)^{\mathrm{b}}$ \\
\hline
\end{tabular}


Table 5: Mean \pm standard error ( $n$ in parentheses) relative tidal heights $(\mathrm{cm})$ across Sesarma grazing intensity zones at five survey marshes. Lower Phillips site was not sampled for relative tidal heights. Values that share superscripted letters, within site, indicate no statistical difference based on ANOVA.

\begin{tabular}{lcccc}
\hline Site & Denuded & Grazed & No Grazing & P-value \\
\hline \hline Boxtree & $34.9 \pm 0.9(8)^{\mathrm{a}}$ & $38.1 \pm 1.7(7)^{\mathrm{a}}$ & $34.8 \pm 1.4(8)^{\mathrm{a}}$ & 0.17 \\
Goodwin Island & $11.4 \pm 1.4(8)^{\mathrm{a}}$ & $16.9 \pm 2.9(8)^{\mathrm{a}}$ & $14.9 \pm 1.9(8)^{\mathrm{a}}$ & 0.22 \\
Lower Phillips & --- & -- & --- & --- \\
Prudence Island & $47.3 \pm 1.2(8)^{\mathrm{a}}$ & $45.9 \pm 0.9(8)^{\mathrm{a}}$ & $39.5 \pm 1.2(8)^{\mathrm{b}}$ & $\mathbf{0 . 0 0 0 2}$ \\
Wellfleet & $61.1 \pm 2.8(8)^{\mathrm{a}}$ & $56.7 \pm 1.8(8)^{\mathrm{a}}$ & $54.9 \pm 2.5(8)^{\mathrm{a}}$ & 0.19 \\
\hline
\end{tabular}




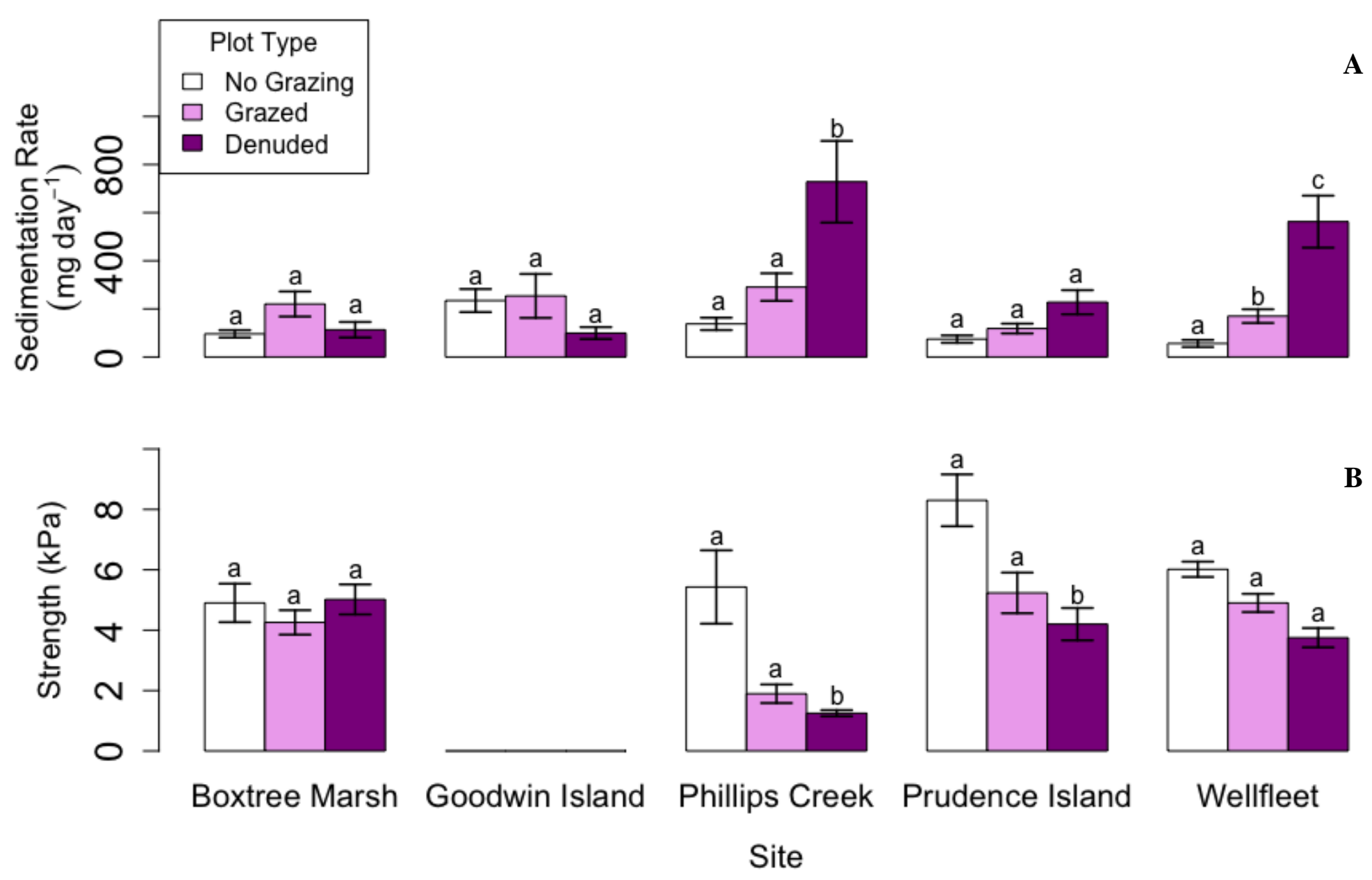

Figure 7: Mean A) sedimentation rates and B) soil strength across Sesarma grazing intensity and sites. Error bars represent standard error. Due to significant interaction between grazing intensity and plot type $(\mathrm{P}<<0.001)$, bars that share a letter within site indicate no statistical difference. Analyses were performed on long-transformed data. Data above is untransformed. 


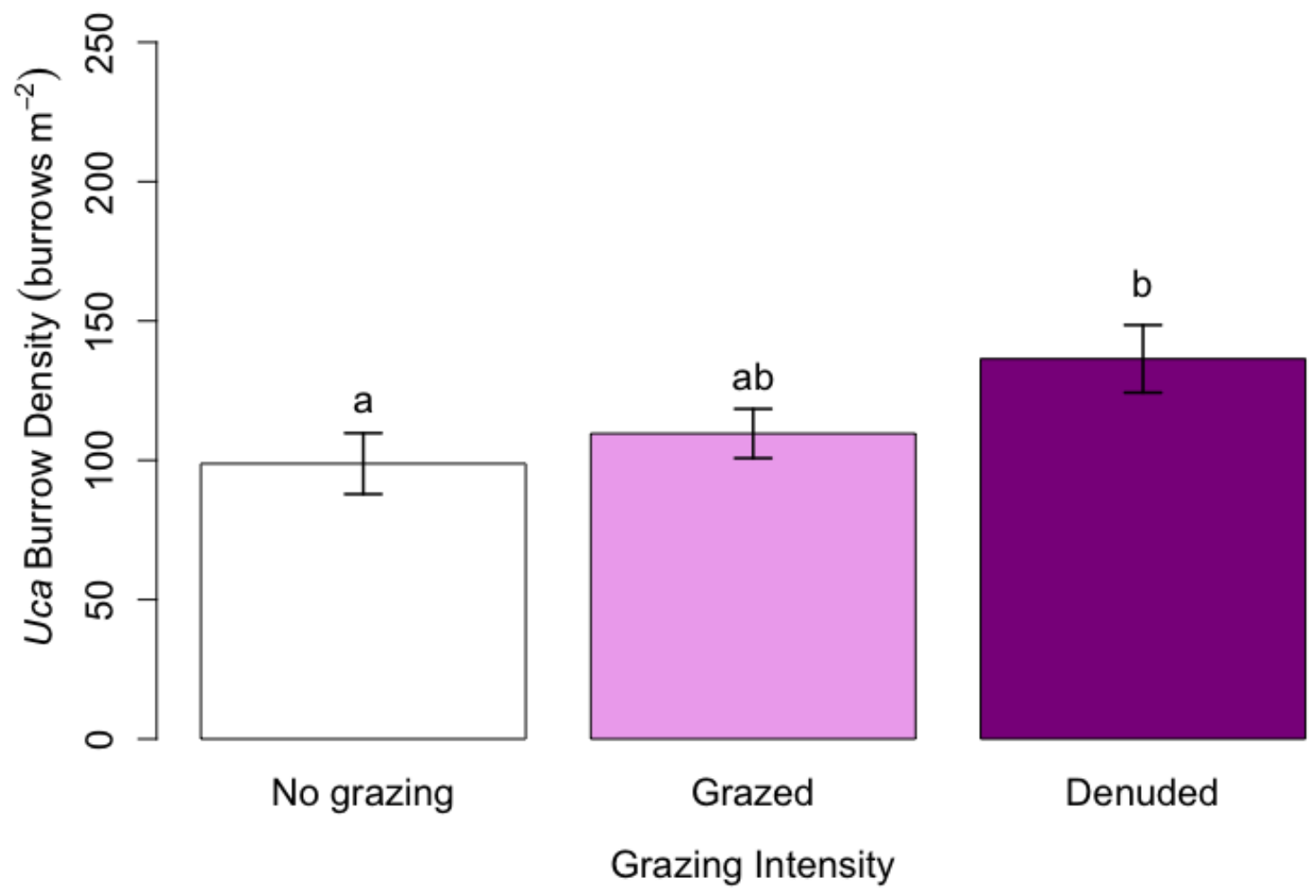

Figure 8: Mean Uca burrow density across Sesarma grazing intensity ( $\mathrm{n}=40$ per intensity). Bars that share a letter indicate no statistical difference based on post-hoc analysis $(\mathrm{P}>0.05)$. Error bars represent standard error. 
Table 6: Mean Sesarma burrow densities (burrows $\mathrm{m}^{-2}$ ) across grazing intensity plots and sites. Site densities were calculated from haphazard burrow enumerations.

\begin{tabular}{lcccc}
\hline Site & Denuded & Grazed & No Grazing & Site \\
\hline \hline Boxtree & $12 \pm 5(8)$ & $0 \pm 0(8)$ & $0 \pm 0(8)$ & $17.6 \pm 5.6(10)$ \\
Goodwin Island & $16 \pm 4(8)$ & $2 \pm 2(8)$ & $6 \pm 4(8)$ & $4.8 \pm 2.4(10)$ \\
Lower Phillips & $2 \pm 2(8)$ & $0 \pm 0(8)$ & $0 \pm 0(8)$ & $0 \pm 0(10)$ \\
Prudence Island & $0 \pm 0(8)$ & $2 \pm 2(8)$ & $4 \pm 3(8)$ & $1.6 \pm 1.6(10)$ \\
Wellfleet & $2 \pm 2(8)$ & $10 \pm 3(8)$ & $0 \pm 0(8)$ & $3.2 \pm 2.1(10)$ \\
\hline
\end{tabular}



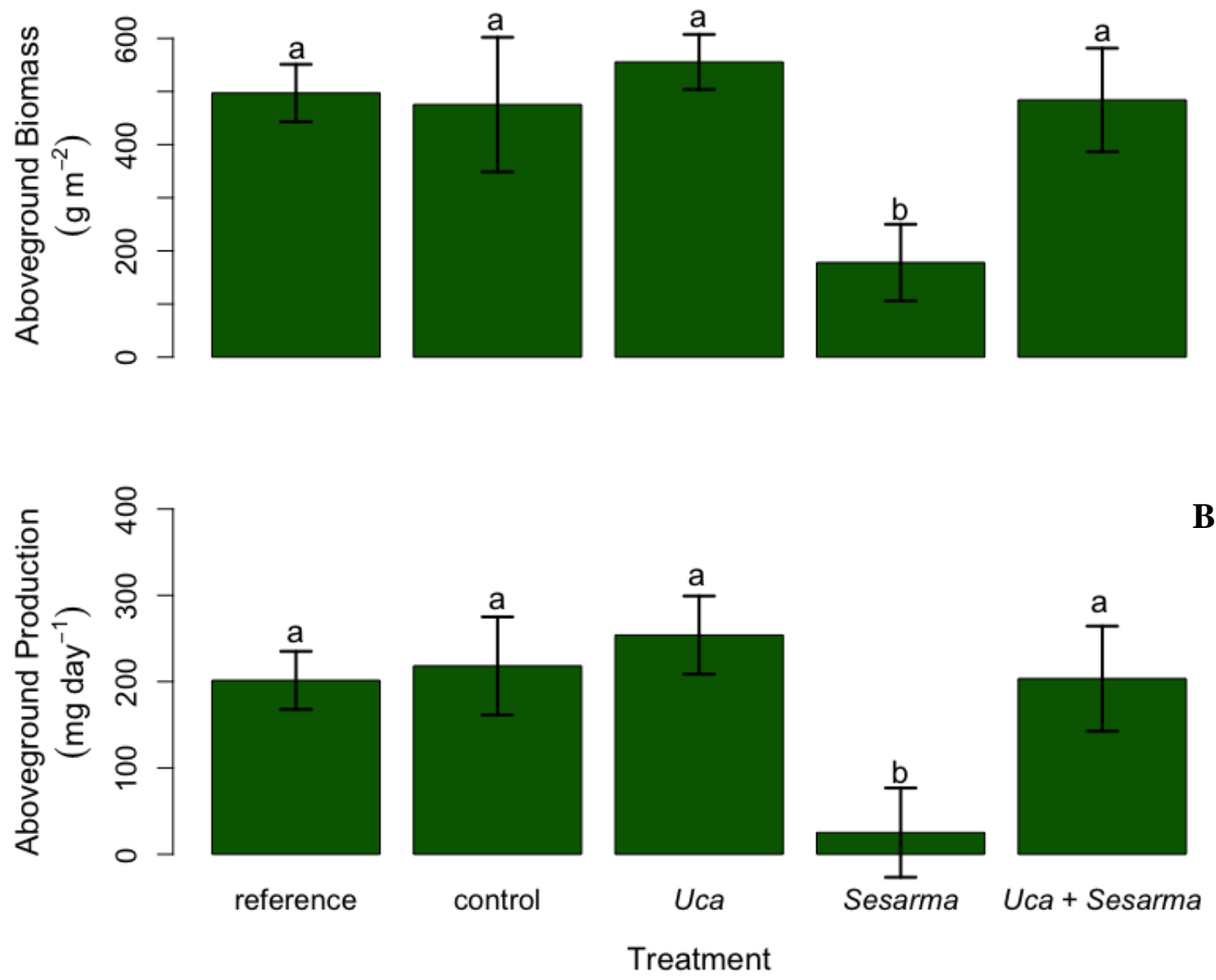

Figure 9. Mean Spartina alterniflora aboveground A) biomass and B) production across cage treatments. Error bars represent standard error. Bars that share letter indicate no statistical difference based on linear mixed effects model. 


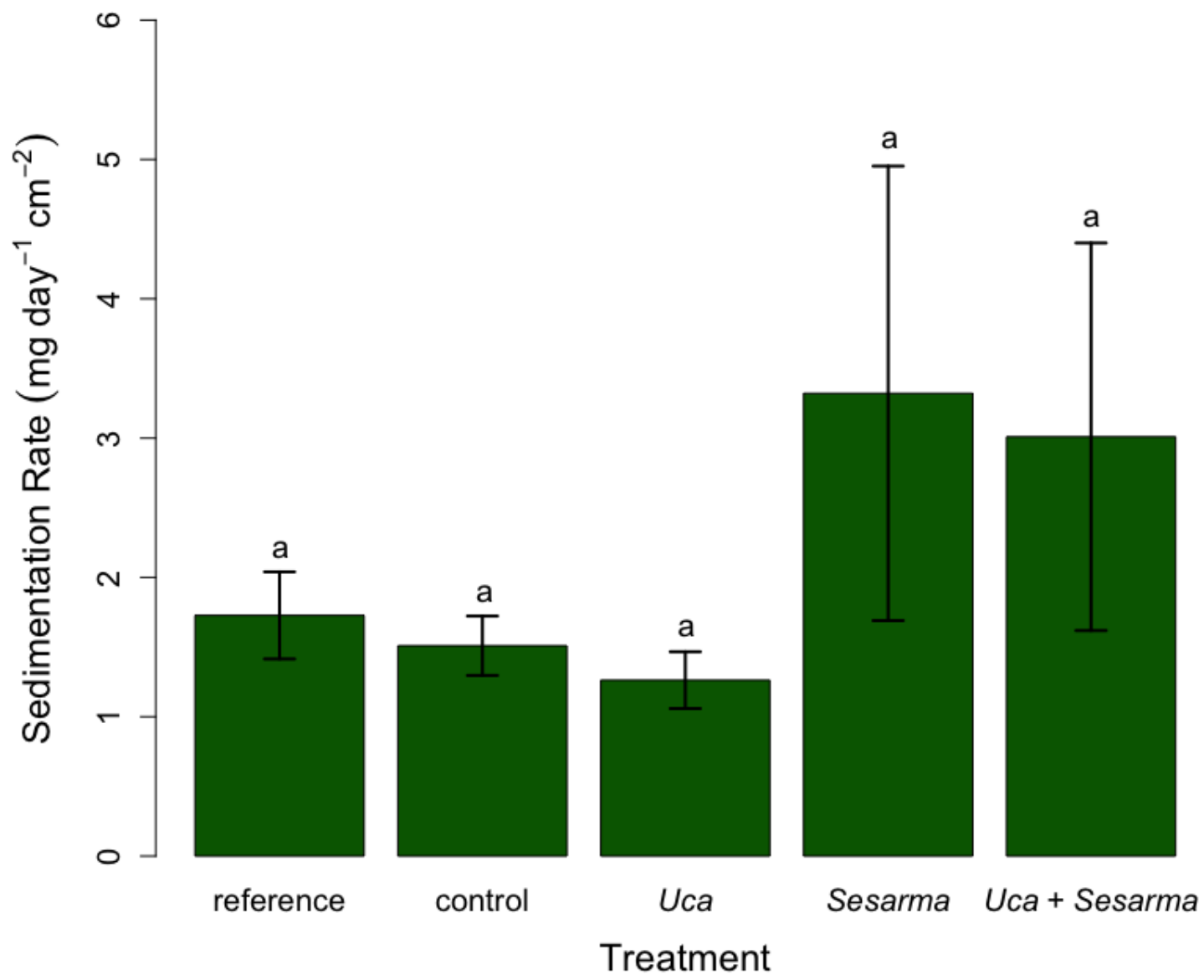

Figure 10: Mean sedimentation rates across cage treatments. Error bars represent standard error. Bars that share a letter indicate no statistical difference, based on analysis of natural log-transformed data in linear mixed effects model. 


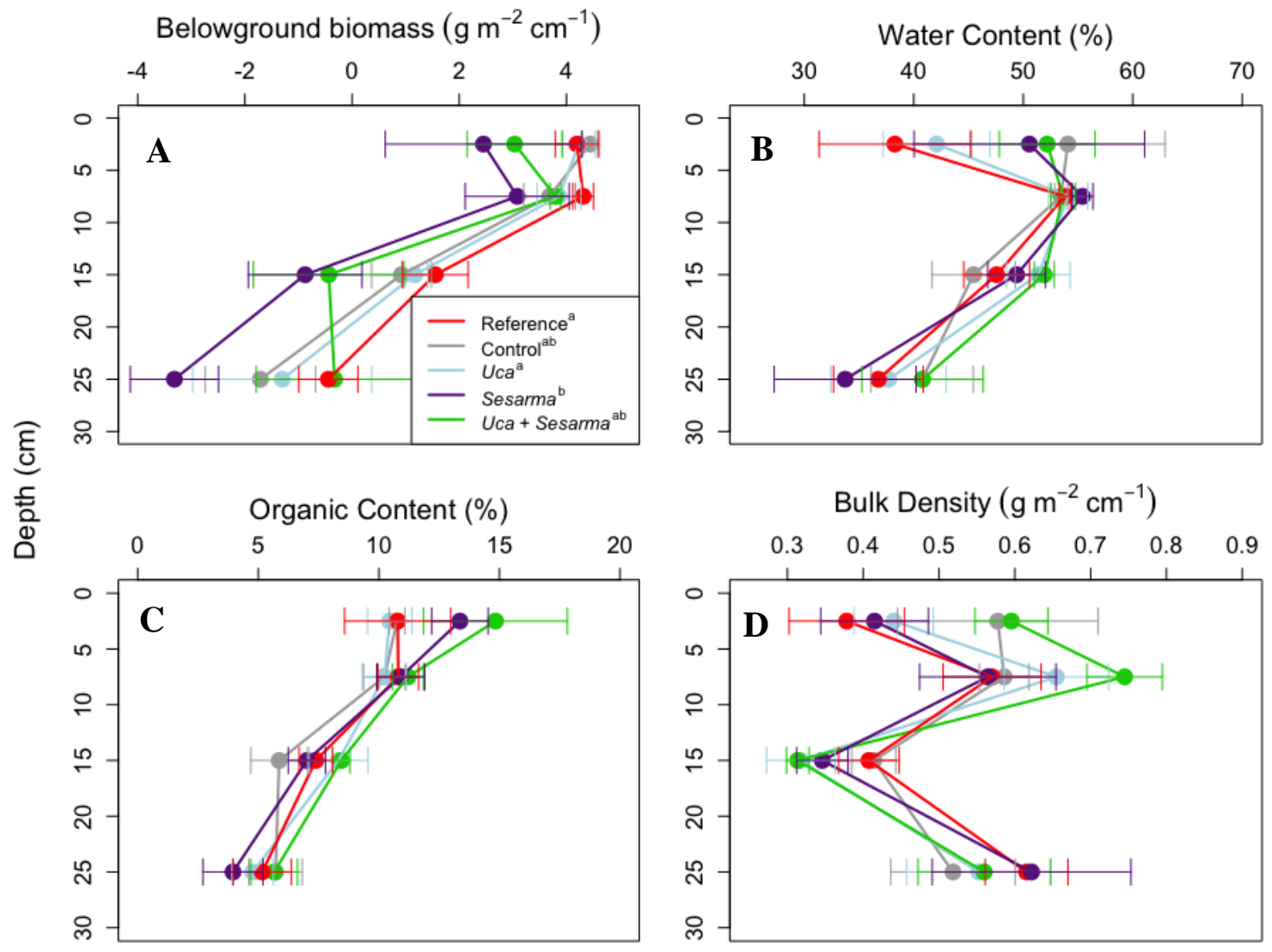

Figure 11: Mean A) live belowground biomass (natural log +0.01 transformed) B) water content, C) organic content, and D) bulk density across cage treatments and depths. Treatments that share letter in the legend indicate no statistical difference based on linear mixed effects model. Responses in plots without a legend have no difference across treatments. Error bars represent standard error. 


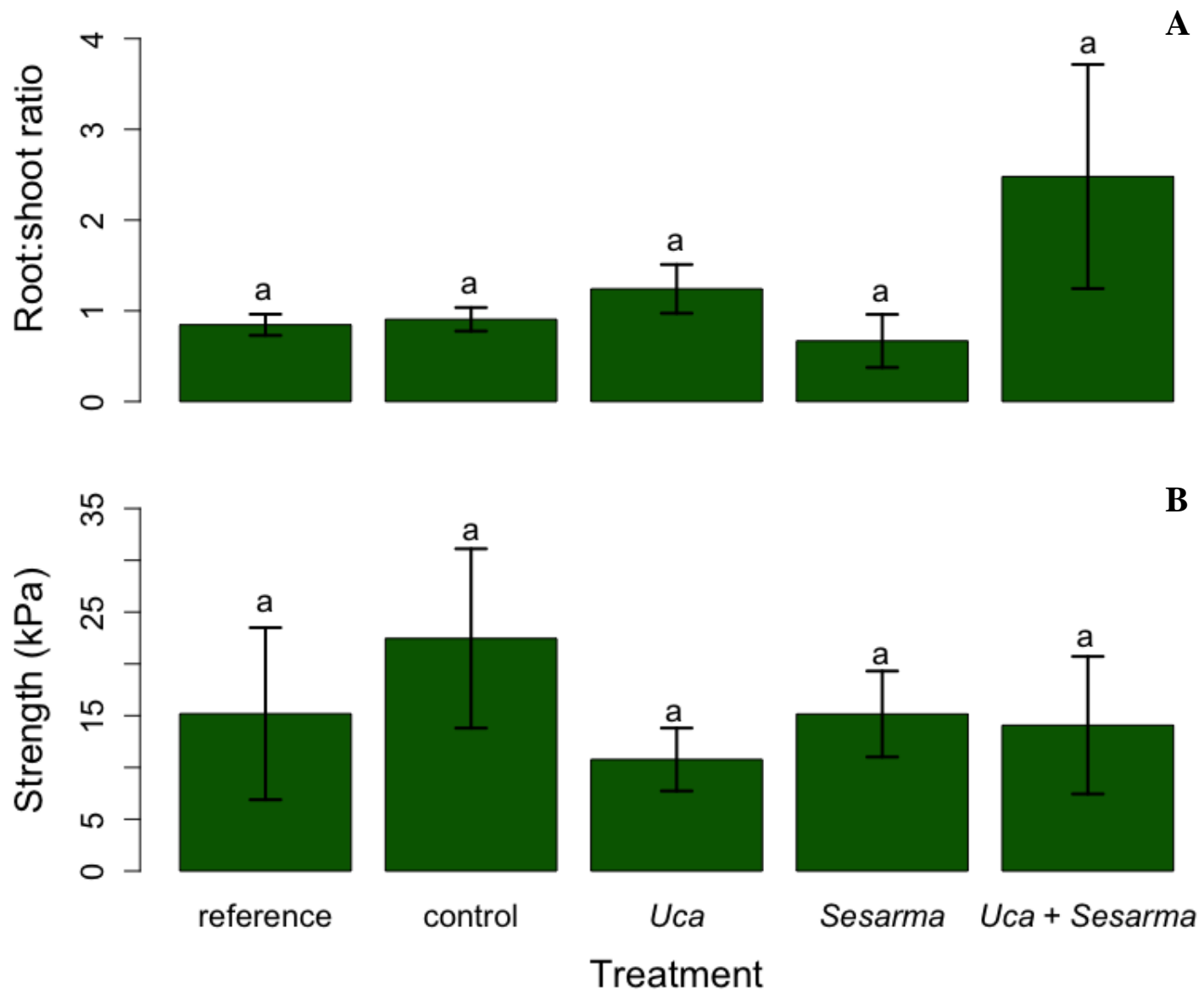

Figure 12: A) Mean Spartina alterniflora root-to-shoot ratio across cage treatments. Value greater than 1 indicates more roots than shoots, while a value less than 1 indicates more shoots than roots. B) Mean soil strength across cage treatments. Error bars represent standard errors. Bars that share a letter indicate no statistical difference based on linear mixed effects model. 

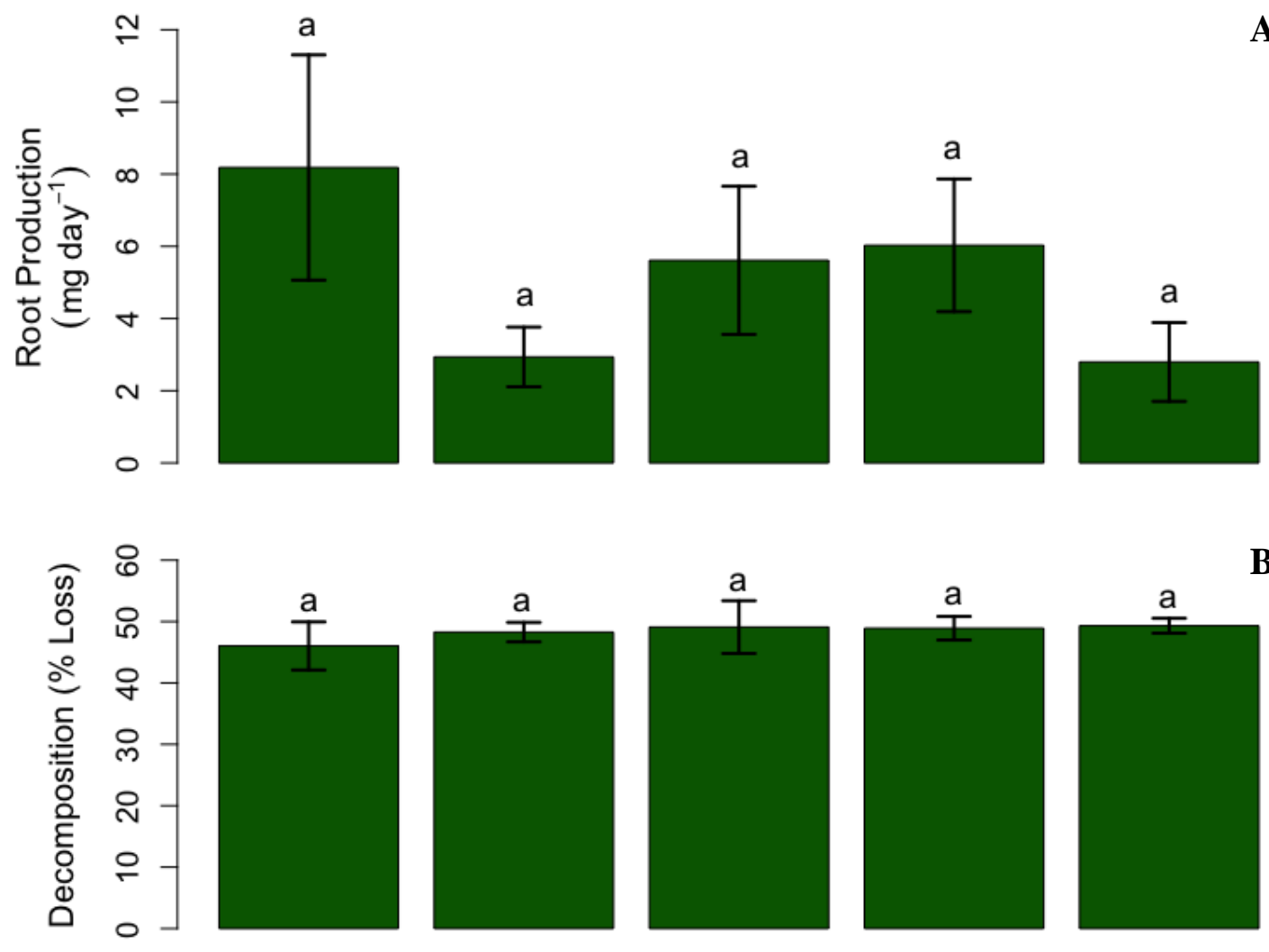

reference

control

Uca

Sesarma

Uca + Sesarma

Treatment

Figures 13: Belowground processes across cage treatments. A) Mean Spartina alterniflora root production and B) Mean decomposition of Spartina roots and rhizomes. Error bars represent standard error. Bars that share a letter represent no statistical difference based on linear mixed effects model. 


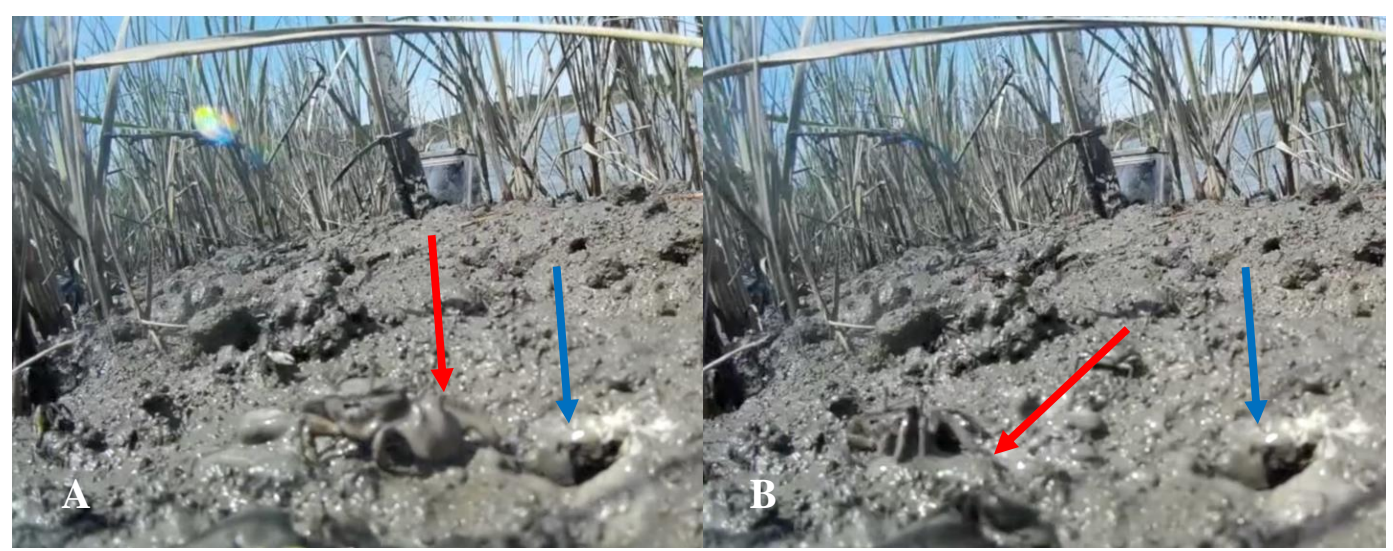

Figure 14: In situ capture of female Uca excavating a burrow. A) Uca carrying mud from burrow and B) mud deposited on marsh surface by $U c a$. Images are 3 seconds apart and captured from a GoPro video. Red arrows point to sediment carried by crab. Blue arrow points to burrow excavated from. Video taken at Lower Phillips Creek marsh, July 2017. 